\title{
Daily Landsat-scale evapotranspiration estimation over a forested landscape in North Carolina, USA, using multi-satellite data fusion
}

\author{
Yun Yang ${ }^{1}$, Martha C. Anderson ${ }^{1}$, Feng Gao ${ }^{1}$, Christopher R. Hain ${ }^{2}$, Kathryn A. Semmens ${ }^{3}$, William P. Kustas ${ }^{1}$, \\ Asko Noormets ${ }^{4}$, Randolph H. Wynne ${ }^{5}$, Valerie A. Thomas ${ }^{5}$, and Ge Sun ${ }^{6}$ \\ ${ }^{1}$ USDA ARS, Hydrology and Remote Sensing Laboratory, Beltsville, MD, USA \\ ${ }^{2}$ Marshall Space Flight Center, Earth Science Branch, Huntsville, AL, USA \\ ${ }^{3}$ Nurture Nature Center, Easton, PA, USA \\ ${ }^{4}$ Department of Forestry and Environmental Resources, North Carolina State University, Raleigh, NC, USA \\ ${ }^{5}$ Department of Forest Resources and Environmental Conservation, Virginia Polytechnic Institute and State University, \\ Blacksburg, VA, USA \\ ${ }^{6}$ Eastern Forest Environmental Threat Assessment Center, Southern Research Station, USDA Forest Service, \\ Raleigh, NC, USA
}

Correspondence to: Yun Yang (yun.yang@ars.usda.gov)

Received: 27 April 2016 - Discussion started: 1 June 2016 Accepted: 19 January 2017 - Published: 17 February 2017

\begin{abstract}
As a primary flux in the global water cycle, evapotranspiration (ET) connects hydrologic and biological processes and is directly affected by water and land management, land use change and climate variability. Satellite remote sensing provides an effective means for diagnosing ET patterns over heterogeneous landscapes; however, limitations on the spatial and temporal resolution of satellite data, combined with the effects of cloud contamination, constrain the amount of detail that a single satellite can provide. In this study, we describe an application of a multi-sensor ET data fusion system over a mixed forested/agricultural landscape in North Carolina, USA, during the growing season of 2013. The fusion system ingests ET estimates from the Two-Source Energy Balance Model (TSEB) applied to thermal infrared remote sensing retrievals of land surface temperature from multiple satellite platforms: hourly geostationary satellite data at $4 \mathrm{~km}$ resolution, daily $1 \mathrm{~km}$ imagery from the Moderate Resolution Imaging Spectroradiometer (MODIS) and biweekly Landsat thermal data sharpened to $30 \mathrm{~m}$. These multiple ET data streams are combined using the Spatial and Temporal Adaptive Reflectance Fusion Model (STARFM) to estimate daily ET at $30 \mathrm{~m}$ resolution to investigate seasonal water use behavior at the level of individual forest stands and land cover patches. A new method, also exploiting the STARFM algorithm, is used to fill gaps in the Land-
\end{abstract}

sat ET retrievals due to cloud cover and/or the scan-line corrector (SLC) failure on Landsat 7. The retrieved daily ET time series agree well with observations at two AmeriFlux eddy covariance flux tower sites in a managed pine plantation within the modeling domain: US-NC2 located in a mid-rotation (20-year-old) loblolly pine stand and USNC3 located in a recently clear-cut and replanted field site. Root mean square errors (RMSEs) for $\mathrm{NC} 2$ and $\mathrm{NC} 3$ were 0.99 and $1.02 \mathrm{~mm} \mathrm{day}^{-1}$, respectively, with mean absolute errors of approximately $29 \%$ at the daily time step, $12 \%$ at the monthly time step and $0.7 \%$ over the full study period at the two flux tower sites. Analyses of water use patterns over the plantation indicate increasing seasonal ET with stand age for young to mid-rotation stands up to 20 years, but little dependence on age for older stands. An accounting of consumptive water use by major land cover classes representative of the modeling domain is presented, as well as relative partitioning of ET between evaporation $(E)$ and transpiration $(T)$ components obtained with the TSEB. The study provides new insights about the effects of management and land use change on water yield over forested landscapes. 


\section{Introduction}

Evapotranspiration (ET) is a major component of the water balance and connects hydrologic and biological processes (Hanson et al., 2004; Wilson et al., 2001). ET varies with climate, vegetation type and phenological stage and is directly affected by land management strategies and climate change (Pereira et al., 2002). ET is also a key variable in most ecohydrological models and ecosystem service assessments (Abramopoulos et al., 1988; Kannan et al., 2007; Olioso et al., 1999; Tague and Band, 2004; Sun et al., 2011a, b). In spite of the importance of ET, routine estimation of ET at high spatial (plot level) and temporal (daily) resolution has not yet been achieved with acceptable accuracy over landscape and regional scales (Wang and Dickinson, 2012).

Current forest ET estimation methods span a range of spatial scales: from individual plants, to tower footprints, to watershed scales (Fang et al., 2015). These methods include in situ measurement, simulation using hydrologic and land surface models which are normally driven by weather data and estimation from satellite remote sensing data. Techniques for measuring ET include weighing lysimeters (Wullschleger et al., 1998), sap flow (Klein et al., 2014; Smith and Allen, 1996) and plant chambers (Cienciala and Lindroth, 1995), soil water budgets (Cuenca et al., 1997), eddy covariance (EC; Baldocchi et al., 2001) and catchment water balance (Pan et al., 2012). While EC is a widely used observation method and provides an important data source to many research fields (Baldocchi et al., 2001), it measures turbulent fluxes over a relatively small footprint area $\left(10^{2}-10^{4} \mathrm{~m}^{2}\right)$, which is determined by the microclimate conditions around the flux tower and the instrument height. Catchment water balance is also a frequently used method, calculating ET from long-term precipitation and streamflow observations with the assumption that the soil water storage change is negligible (Domec et al., 2012; Wilson et al., 2001). All these observation methods have their inherent advantages and limitations, especially when considering both temporal and spatial resolution issues.

Another group of forest ET estimation methods is empirically based, establishing a relationship between ET with other parameters: for example, precipitation, reference ET and vegetation indices (leaf area index - LAI, normalized difference vegetation index - NDVI and enhanced vegetation index - EVI) (Johnson and Trout, 2012; Mutiibwa and Irmak, 2013; Nemani and Running, 1988; Sun et al., 2011a; Zhang et al., 2004). Many studies have applied process-based ecohydrological models to estimate ET (Chen and Dudhia, 2001; Tague and Band, 2004; Tian et al., 2010). These models usually estimate ET from potential ET, which is then downregulated based on weather data and soil and vegetation characteristics. However, with the focus on predicting runoff and the soil water profile, studies using hydrologic models generally do not evaluate the performance of ET simulation. To simplify the physical processes, many models as- sume the plant growth rate is static. This assumption can result in errors in simulating ET dynamics, especially over shorter time periods (seasonally, monthly, weekly or daily) (Méndez-Barroso et al., 2014; Tian et al., 2010). Often physical process-based models involve hundreds of input variables/parameters, many of which are not easily measured or known in a spatially distributed manner at watershed and regional scales. Although models can be calibrated using local or watershed-scale observations, there is the often-mentioned problem of equifinality, where different sets of parameters during calibration give the same simulation results due to the inherent complexity of the system (Von Bertalanffy, 1968; Beven and Freer, 2001).

Mapping ET using satellite remote sensing data has been widely applied since the 1980s due to growing interest in the spatial dynamics of water use at the watershed and regional scales (Kalma et al., 2008). Of particular interest in the water resource community are surface energy balance methods based on remotely sensed land-surface temperature (LST) retrieved from thermal infrared (TIR) imagery, which provides proxy information regarding the surface moisture status (Hain et al., 2011; Anderson et al., 2012a). LST captures signals of crop stress and variable soil evaporation that are often missed by crop coefficient remote sensing techniques, which are based on empirical regressions with reflectancebased vegetation indices. Furthermore, diagnostic estimates of ET from the surface energy balance provide an independent estimate of landscape water use that is a valuable benchmark for comparison with estimates based on water balance or hydrologic modeling (Hain et al., 2015; Yilmaz et al., 2014). Finally, the range in spatial resolution and coverage of existing TIR data sources enables mapping of ET from the plot or field scale $(<100 \mathrm{~m}$ resolution) up to continental or global coverage at $1-5 \mathrm{~km}$ resolution.

The Atmosphere-Land Exchange Inverse Model (ALEXI; Anderson et al., 1997, 2007a, b) and associated flux disaggregation algorithm (DisALEXI; Anderson et al., 2004; Norman et al., 2003) are examples of a multiscale energy balance modeling approach that can utilize LST data from multiple satellite platforms with TIR sensing capabilities. The regional ALEXI model uses time-differential measurements of morning LST rise from geostationary satellites to estimate daily flux patterns at $3-10 \mathrm{~km}$ resolution and continental scales. Using higher-resolution LST information from polar-orbiting systems, DisALEXI enables downscaling of ALEXI fluxes to finer scales, better resolving land use and moisture patterns over the landscape and better approximating the spatial scale of ground-based flux observations. Landsat data $(30-120 \mathrm{~m})$ can be used to retrieve ET at the field scale, which is particularly useful for water management applications. However, due to the lengthy revisit interval ( 8 to 16 days), further lengthened by cloud contamination, the number of useful Landsat scenes that can be acquired during a growing season is limited. The Moderate Resolution Imaging Spectroradiometer (MODIS) has a shorter revisit inter- 


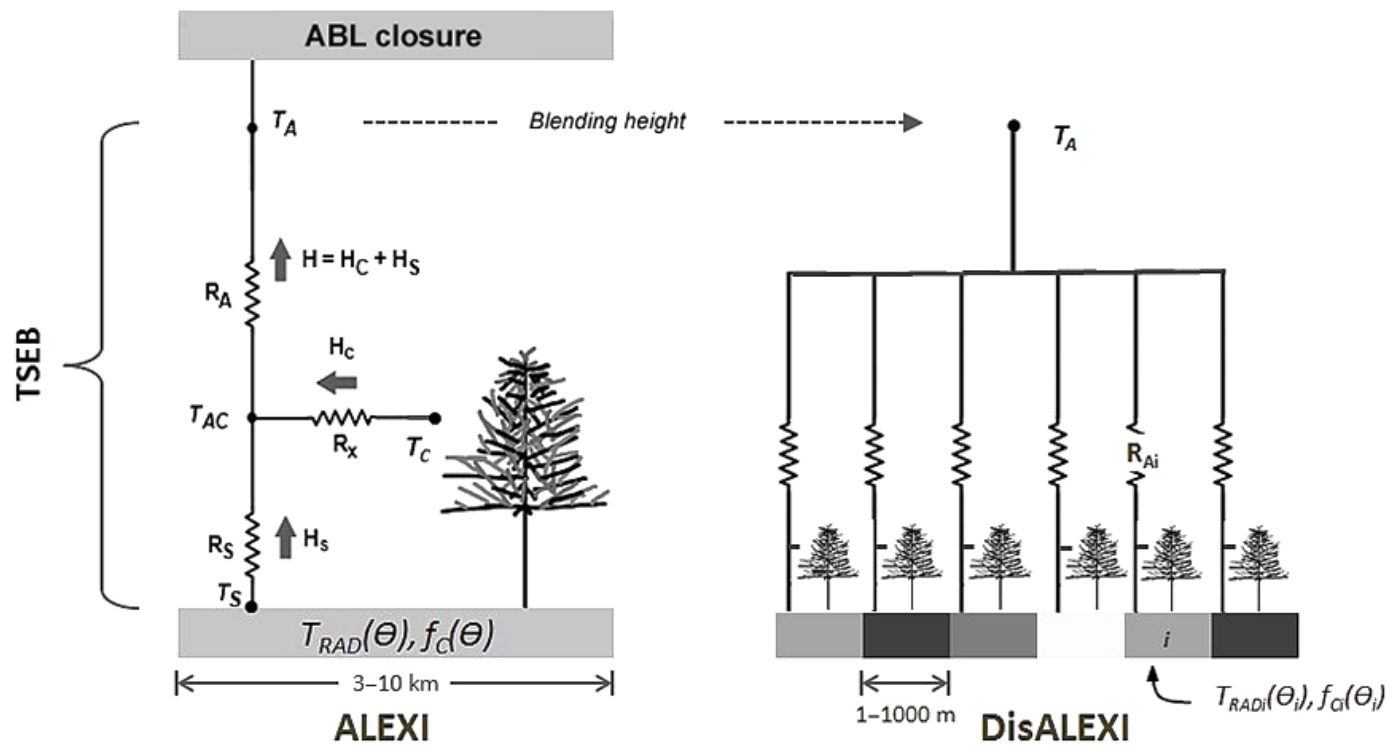

Figure 1. Schematic diagram of the ALEXI and DisALEXI modeling schemes. The left panel shows TSEB as employed to partition the income radiometric temperature $\left(T_{\mathrm{RAD}}(\theta), \theta\right.$ is view angle) into canopy (subscript "c") and soil (subscript "s") components based on vegetation coverage $(f(\theta))$. Sensible heat $(H)$ is regulated by the aerodynamic resistance $\left(R_{\mathrm{a}}\right)$, bulk leaf boundary layer resistance $\left(R_{X}\right)$ and soil surface boundary layer resistance $\left(R_{\mathrm{S}}\right)$. ALEXI combines the TSEB and ABL models to estimate air temperature $\left(T_{\mathrm{A}}\right)$ at the blending height. The right panel represents the disaggregation of ALEXI output to finer scales based on LST and $f(\theta)$ information from Landsat and MODIS.

val (approximately daily) but is too coarse (1 km in the TIR bands) for field-scale ET estimation. Cammalleri et al. (2013) proposed a data fusion method to combine ET estimates derived from geostationary, MODIS and Landsat TIR data, attempting to exploit the spatiotemporal advantages of each class of satellite to map daily ET at a sub-field scale. This ET fusion approach has been successfully applied over rainfed and irrigated corn, soybean and cotton fields (Cammalleri et al., 2013, 2014), as well as irrigated vineyards (Semmens et al., 2015). The work described here constitutes the first application to forest land cover types, representing a substantially different roughness and physiological regime than that of shorter crops. This presents a modeling challenge in terms of accurately defining turbulent exchange coefficients, as well as describing radiation transport through the canopy.

In this paper, ALEXI and DisALEXI are applied over a commercially managed loblolly pine (Pinus taeda) plantation, representing a range in stand age, to estimate daily fieldscale ET using the data fusion methodology. Retrieved $30 \mathrm{~m}$ ET time series are evaluated at two flux tower sites, sited in mature and recently clear-cut pine stands. The primary science objectives are to (1) study the accuracy of ALEXI and DisALEXI ET retrievals over forested sites, (2) evaluate the models' ability to capture the dynamics of fluxes over the contrasting canopy structures in both pine and the adjacent vegetation and (3) investigate the utility of daily field-scale ET retrievals for water resource management in forested systems. Additionally, we present a novel methodological ad- vancement, based on data fusion, for filling gaps in Landsatbased ET retrievals due to partial cloud cover as well as the scan-line corrector (SLC) failure in Landsat 7. This technique facilitates more complete use of the existing Landsat archive for investigating water use dynamics at the landscape scale.

\section{Methods}

\subsection{Thermal-based multiscale ET retrieval}

The regional ALEXI and the associated DisALEXI models are based on the the Two-Source Energy Balance (TSEB) land-surface representation of Norman et al. (1995), with further refinements by Kustas and Norman (1999, 2000). The combined modeling system is described schematically in Fig. 1. Rather than treating the land surface as a homogeneous surface, the TSEB partitions modeled surface fluxes and observed directional radiometric surface temperature between soil and vegetation components:

$T_{\mathrm{RAD}}(\varnothing)^{4}=f(\varnothing) T_{\mathrm{c}}^{4}+[1-f(\varnothing)] T_{\mathrm{s}}^{4}$,

where $\varnothing$ is the thermal view angle, $f(\varnothing)$ is the fractional vegetation cover apparent at the thermal view angle, $T_{\mathrm{RAD}}$ is the directional radiometric temperature, $T_{\mathrm{c}}$ is the canopy temperature and $T_{\mathrm{S}}$ is the soil temperature $(\mathrm{K})$. In remote sensing applications, $f(\varnothing)$ can be estimated from retrievals of LAI 
using the Beer-Lambert law. The surface energy balance for the canopy, soil and the combined system is represented in Eq. (2):

$$
\begin{aligned}
& R_{\mathrm{n}, \mathrm{s}}=H_{\mathrm{s}}+\lambda E_{\mathrm{s}}+G \\
& R_{\mathrm{n}, \mathrm{c}}=H_{\mathrm{c}}+\lambda E_{\mathrm{c}} \\
& R_{\mathrm{n}}=H+\lambda E+G,
\end{aligned}
$$

where the subscripts "c" and "s" represent fluxes from the canopy and soil components, and $R_{\mathrm{n}}$ is net radiation, $\lambda E$ is latent heat flux, $H$ is sensible heat and $G$ is the soil heat flux (all in units of $\mathrm{W} \mathrm{m}^{-2}$ ). Component surface temperatures in Eq. (1) are used to constrain $R_{\mathrm{n}}, H$ and $G$; canopy transpiration $\left(\lambda E_{\mathrm{c}}\right)$ is initially estimated with a modified PriestleyTaylor approach under the unstressed conditions assumption, and then iteratively downregulated if $T_{\mathrm{c}}$ indicates canopy stress, ruled by the assumption that condensation under daytime clear-sky conditions is unlikely, while soil evaporation $\left(\lambda E_{\mathrm{s}}\right)$ is computed as a residual to the soil energy budget. Further information regarding the TSEB model formulation is provided by Kustas and Anderson (2009).

Roughness length $\left(Z_{m}\right)$ impacts the aerodynamic resistance $\left(R_{\mathrm{a}}\right)$, which is the resistance to heat transport across the layer between the nominal momentum exchange surface within the canopy and the height of the air temperature boundary condition $\left(Z_{T}(\mathrm{~m})\right)$. The aerodynamic resistance $\left(R_{\mathrm{a}}\right)$ can be expressed as Eq. (3) (Brutsaert, 1982):

$$
R_{\mathrm{a}}=\frac{\left[\ln \left(\frac{Z_{T}-d}{Z_{m}}\right)-\psi_{\mathrm{h}}\right]\left[\ln \left(\frac{Z_{u}-d}{Z_{m}}\right)-\psi_{\mathrm{m}}\right]}{k^{2} u},
$$

where $k$ is the von Karman constant $(0.4) ; u\left(\mathrm{~m} \mathrm{~s}^{-1}\right)$ is the wind speed measured at height $Z_{u}(\mathrm{~m}) ; d(\mathrm{~m})$ is the displacement height; $Z_{m}(\mathrm{~m})$ is the roughness length, which can be estimated from the nominal canopy height $\left(h_{\mathrm{c}}(\mathrm{m})\right)$, $Z_{m} \approx h_{\mathrm{c}} / 8$ (Shaw and Pereira, 1982); and $\psi_{\mathrm{h}}$ and $\psi_{\mathrm{m}}$ are the stability corrections for heat and momentum transport, respectively. Additional boundary layer resistances linking the bulk canopy and the soil surface to the in-canopy momentum exchange node ( $R_{\mathrm{X}}$ and $R_{\mathrm{S}}$, respectively; see Fig. 1$)$ are defined as in the series TSEB model formulation described in Norman et al. (1995).

The regional-scale ALEXI model applies the TSEB in time-differential mode using measurements of morning LST rise obtained from geostationary platforms (Anderson et al., 1997, 2007a). Energy closure over this morning period is obtained by coupling the TSEB with a simple model of atmospheric boundary layer (ABL) development (Fig. 1). In this study, instantaneous morning fluxes from ALEXI have been upscaled to daily total latent heat flux by conserving the ratio of $\lambda E$ to solar radiation, following the recommendations of Cammalleri et al. (2014). Daily latent heat flux (in energy units of $\mathrm{MJ} \mathrm{m}^{-2}$ day $^{-1}$ ) is converted to ET (in mass units of $\mathrm{mm} \mathrm{day}^{-1}$ ) by dividing by the latent heat of vaporization $\left(\lambda=2.45 \mathrm{MJ} \mathrm{kg}^{-1}\right)$.
This time-differential approach used in ALEXI reduces model sensitivity to errors in LST retrieval due to atmospheric and surface emissivity effects, but it does constrain ET estimates to the relatively coarse spatial scales typical of geostationary satellites. To estimate ET at the finer scales required for many management applications, the ALEXI fluxes can be spatially disaggregated using the DisALEXI approach (Anderson et al., 2004; Norman et al., 2003). DisALEXI uses, as an initial estimate, air temperature estimates diagnosed by ALEXI at a nominal blending height at the interface between the TSEB and ABL submodels, along with high spatial resolution images of surface temperature data and vegetation cover fraction from polar-orbiting or airborne systems, to run the TSEB at sub-pixel scales over each ALEXI pixel area. The TSEB fluxes are reaggregated and compared with the ALEXI pixel flux, and the air temperature boundary condition is iteratively modified until the fluxes are consistent at the ALEXI pixel scale. More details on the ALEXI/DisALEXI multiscale modeling system can be found in Anderson et al. (2004, 2011, 2012b).

\subsection{Data processing and fusion system}

In this study, ET retrievals generated with DisALEXI using TIR data from MODIS (near daily, at $1 \mathrm{~km}$ resolution) and Landsat (periodic, sharpened to $30 \mathrm{~m}$ resolution) have been fused to produce daily Landsat-scale ET time series. The major components of the processing stream are described in greater detail below, including a data-mining sharpener (DMS; Gao et al., 2012b) tool that is used to improve the spatial resolution of the LST inputs to DisALEXI, the Spatial and Temporal Adaptive Reflectance Fusion Model (STARFM; Gao et al., 2006) and a gap-filling procedure that is applied to ALEXI and MODIS and Landsat-DisALEXI retrievals prior to disaggregation and fusion. The gap-filling and fusion processes are schematically represented in Fig. 2.

\subsubsection{Data-mining sharpener (DMS)}

In both the Landsat and MODIS imaging systems, the TIR sensors have significantly lower spatial resolution than the shortwave instruments on the same platform. For Landsat, TIR resolution varies from $60 \mathrm{~m}$ (Landsat 7) to $100 \mathrm{~m}$ (Landsat 8 ) to $120 \mathrm{~m}$ (Landsat 5), while the shortwave images are processed to $30 \mathrm{~m}$. For MODIS, TIR resolution is $1 \mathrm{~km}$ while the shortwave resolution is $250 \mathrm{~m}$. Particularly for Landsat, there is a benefit to mapping ET at $30 \mathrm{~m}$ rather than the native TIR resolution, as boundaries in land cover and moisture variability are much better defined.

The DMS sharpening tool implemented within the ET fusion package enables this higher-resolution mapping. The DMS technique creates regression trees between TIR band brightness temperatures and shortwave spectral reflectances both globally across the full scene and within a localized moving window (Gao et al., 2012b). The original TIR data 


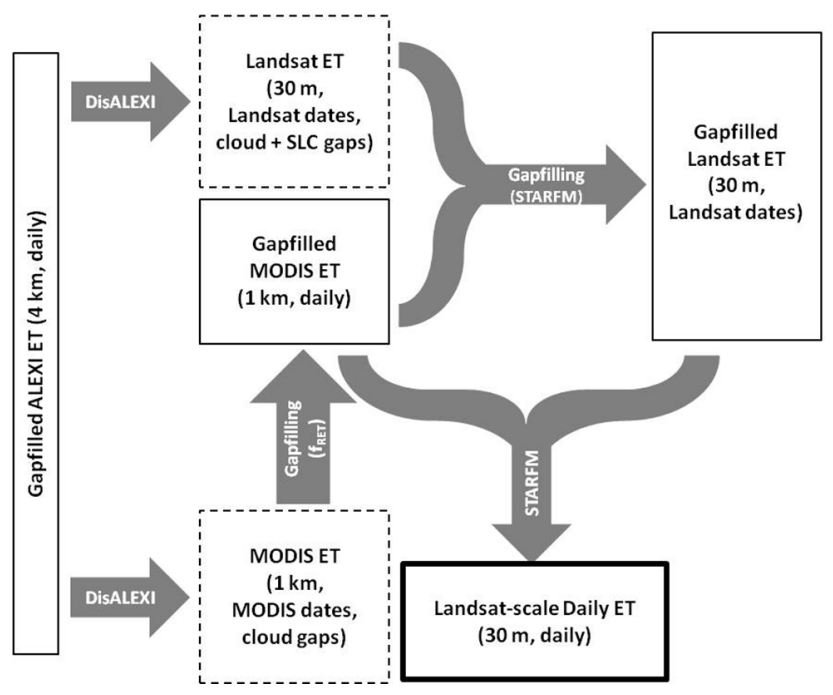

Figure 2. Flowchart describing the Landsat gap-filling and data fusion method. The arrows represent the methods applied. The boxes represent the datasets with different spatial and temporal characteristics created during the process. The dashed boxes indicate ET products with partially filled scenes (due to clouds or SLC gaps); solid boxes identify gap-filled scenes and the thick box highlights the final gap-filled $30 \mathrm{~m}$ daily product.

are sharpened from their native spatial resolution to finer resolution with DMS, with the choice of using all of the available shortwave bands or a subset of these bands or even a single vegetation index as input to the regression tree. The sharpened results from the global and local models are combined based on a weighting factor calculated from the residuals of the two sharpened results.

\subsubsection{Spatial and Temporal Adaptive Reflectance Fusion Model (STARFM)}

The STARFM algorithm fuses spatial information from Landsat imagery with temporal information from the coarser but more frequently collected MODIS imagery to produce daily estimates at Landsat-like scale. STARFM was originally designed for application to surface reflectance images, but has demonstrated utility in fusing higher-order satellite products as well, as long as there is sufficient consistency between the Landsat and MODIS retrievals.

First, ET data from both MODIS and Landsat retrievals are extracted onto a common $30 \mathrm{~m}$ grid. A moving searching window method is then used in STARFM to estimate values at the center pixel of the moving window:

$$
\begin{aligned}
L\left(x_{p / 2} y_{p / 2} t_{0}\right) & =\sum_{i=1}^{p} \sum_{j=1}^{p} \sum_{k=1}^{n} W_{i j k} \times\left(M\left(x_{i}, y_{j}, t_{0}\right)\right. \\
& \left.+L\left(x_{i}, y_{j}, t_{k}\right)-M\left(x_{i}, y_{j}, t_{k}\right)\right),
\end{aligned}
$$

where $p$ is the size of the moving window and $\left(x_{p / 2}, y_{p / 2}\right)$ is the center pixel of the moving window that needs to be es- timated at time $t_{0} .\left(x_{i}, y_{j}\right)$ is the pixel location, $M\left(x_{i}, y_{j}\right.$, $\left.t_{0}\right)$ is the MODIS pixel value at time $t_{0}, M\left(x_{i}, y_{j}, t_{k}\right)$ is the MODIS pixel value at time $t_{k}$ and $L\left(x_{i}, y_{j}, t_{k}\right)$ is the Landsat pixel value at time $t_{k} . W_{i j k}$ is the weighting factor that determines how much each pixel in the moving window contributes to the estimation of the center pixel value. In the ET fusion system, STARFM uses the weighting function derived from Landsat ET and MODIS ET retrieved on the same date and MODIS ET on the prediction date to get Landsat-like ET estimations on all prediction dates between Landsat overpasses.

\subsubsection{ET gap-filling methods}

Spatiotemporal gaps in TIR-based ET retrievals occur for a variety of reasons, including cloud cover, frequency of sensor overpass, limitations imposed to avoid distortions in LST data acquired at large off-nadir view angles and other sensor issues. Prior to disaggregation and fusion, the input ET fields must be gap filled, both spatially and temporally, to the extent possible to ensure relatively gap-free output time series.

Due to the high temporal frequency of data acquisition from both geostationary and MODIS systems, the ALEXI and DisALEXI-MODIS retrievals can be reasonably gap filled and interpolated to daily time steps in all but the cloudiest of circumstances. Time intervals between clear-sky Landsat acquisitions are too lengthy in general, motivating the need for data fusion to fill temporal gaps. Spatial gaps in Landsat ET retrievals have been filled using a method based on STARFM, as described below.

\section{ALEXI and MODIS-DisALEXI}

Gaps in the daily ET maps from ALEXI and MODISDisALEXI were filled using the method described by Anderson et al. (2012b). Daily reference ET is first calculated using the Food and Agriculture Organization (FAO) PenmanMonteith formulation for a grass reference site (Allen et al., $1998)$. The ratio of actual-to-reference ET ( $\left.f_{\mathrm{RET}}\right)$ is computed and then smoothed and gap filled at each pixel using a Savitzky-Golay filter. Gap-filled daily ET is recovered by multiplying this $f_{\text {RET }}$ series by daily reference ET.

\section{Landsat-DisALEXI}

To ensure optimal spatial coverage in the fused $30 \mathrm{~m}$ daily time series, the Landsat-based ET retrievals on Landsat overpass dates must also be gap filled to the extent possible. Gaps in Landsat ET result from cloud cover, or in the case of Landsat 7, missing pixels due to the SLC failure that has been occurring since May 2003, resulting in striped gaps in all but the center of each scene. In the case of Landsat, the time interval between usable overpasses may be too long to justifiably use the $f_{\text {RET }}$ approach applied to the ALEXI and MODIS time series. Therefore, an alternate method has been 
developed to fill cloud gaps/stripes to create filled scenes for ingestion into STARFM.

The method involves running STARFM for the partly cloudy or striped prediction date using Landsat-retrieved ET from surrounding clear dates. The cloud/stripe-impacted areas in the Landsat retrieval are then filled as a weighted function of the STARFM estimated Landsat-like ET and the Landsat-retrieved ET. This weighting is implemented to reduce impacts of bias that may exist between the STARFM estimate and the actual retrieval in the area of the gap, which could otherwise result in a notably patchy fill. The weighting function is computed within a moving window, predicting ET at the center pixel. The weighting value of each pixel in the moving window is calculated based on land cover type, spatial distance to the center predicting pixel and pixel value and is then normalized to a $0-1$ value. Pixels that have the same land cover type as the prediction pixel, are nearby and have a similar value are assigned a higher weighting score. The resulting filled value is computed as

Filled Value $=A_{\mathrm{L}}-A_{\mathrm{S}}+\sum_{i}^{p} \sum_{j}^{p}\left(W_{i, j} \times S_{i, j}\right)$,

where $A_{\mathrm{L}}$ is the average of pixels in the moving window in Landsat-retrieved ET, $A_{\mathrm{S}}$ is the average of pixels in the moving window in STARFM fused ET on the same day as the Landsat-retrieved ET, $i$ and $j$ is the pixel location in the moving window, $p$ is the moving window size, $W$ is the weighting score and $S$ is the STARFM value.

The searching distance is predefined based on the heterogeneity of the study area. A larger searching distance normally requires a longer computing time and can result in more random noise. A searching distance that is too small might not be able to provide a sufficient number of similar surrounding pixels to predict the value of the center pixel. As described above, pixels that are far away from the center pixel have lower weighting than pixels that are close to the center pixel. When the gap area is large and contiguous (more than $80 \%$ of the moving window), there are not enough good pixels that can provide useful information for the gap fill. In this case, the gaps are left unfilled.

Previous Landsat gap-filling techniques have focused on filling spectral reflectance fields. Chen et al. (2011) applied a similar weighting function in a moving window to fill the Landsat 7 SLC-off images using an appropriate thematic mapper (TM) image or SLC-on enhanced thematic mapper plus (ETM+) image. Roy et al. (2008) used both MODIS BRDF/Albedo products and Landsat observations to predict Landsat reflectance with a semi-physical fusion approach. In contrast, the methods described here are a novel application of data fusion to filling SLC-off gaps in ET retrievals.

The cloud mask used in this study is the Fmask (function of mask) data from the Level 2 surface reflectance product distributed by EROS (Earth Resources Observation and Science) center. Fmask uses Landsat top-of-atmosphere re- flectance and brightness temperature as inputs to produce cloud, cloud shadow, water and snow mask for Landsat images (Zhu and Woodcock, 2012). Cloud physical properties are first used to identify potential cloud pixels and clear-sky pixels and then normalized temperature, spectral variability and brightness probability functions are combined to estimate cloudy area. The cloud shadow area is derived from the darkening effect of the cloud shadows in the near-infrared band, view angle of the satellite sensor and the solar illumination angle. In this study, we flagged pixels with Fmask class 2 (cloud_shadow) and 4 (cloud) in the cloud mask file as cloud impacted.

\section{Experimental site and datasets}

\subsection{Study area}

The study area (Fig. 3) is located over the Parker Tract in the lower coastal plain of North Carolina. The Parker Tract consists of loblolly pine plantations of different ages and native hardwood forests (Noormets et al., 2010). The plantations are commercially managed for timber production by the Weyerhaeuser Company. The study area is flat, about $3 \mathrm{~m}$ a.s.l. and has been ditched (fourth-order ditches at $100 \mathrm{~m}$ spacing) to manage the water table and improve tree productivity (Domec et al., 2012). The soil is Belhaven series Histosol, with a $50-85 \mathrm{~cm}$ organic layer over coarse glacial outwash sand (Sun et al., 2010). The study area is classified as outer coastal plain mixed forest province (Bailey, 1995). The long-term (1945-2008) monthly temperature ranges between $26.6^{\circ} \mathrm{C}$ in July and $6.4^{\circ} \mathrm{C}$ in January, with an annual mean temperature of $15.5^{\circ} \mathrm{C}$. The long-term annual precipitation is around $1320 \pm 211 \mathrm{~mm}$, relatively evenly distributed throughout the year.

Evaluation of the DisALEXI ET estimates was performed at two AmeriFlux tower sites in this area: US-NC2 (35$\left.48^{\circ} \mathrm{N}, 76-40^{\circ} \mathrm{W}\right)$ and US-NC3 $\left(35-48^{\circ} \mathrm{N}, 76-39^{\circ} \mathrm{W}\right)$. US$\mathrm{NC} 2$ is a mid-rotation plantation stand with 90 ha area, which was established after clear-cutting a previous rotation of loblolly pine, replanted with 2-year-old seedlings at $1.5 \mathrm{~m}$ by $4.5 \mathrm{~m}$ spacing in 1992 . The stand has been fertilized twice - at establishment and in 2010, following a thinning in 2009. The tree density during the study period in 2013 was 171 trees per hectare with a standing biomass of $42.6 \mathrm{tC} \mathrm{ha}^{-1}$ in the overstory and $6.5 \mathrm{tCha}^{-1}$ in the understory. The understory was composed of red maple, greenbrier and volunteer loblolly pine. US-NC3 was established in 2013 in a stand that was clear-cut in 2012, located approximately $1.5 \mathrm{~km}$ from US-NC2. US-NC3 was replanted with seedling loblolly pines after the clear cut. Trees in the US-NC2 site were 22 years old in 2013, were $19.0 \mathrm{~m}$ tall and had a mean LAI of $3.77 \mathrm{~m}^{2} \mathrm{~m}^{-2}$, whereas NC3 was freshly planted with 2-year-old seedlings, which were $0.2 \mathrm{~m}$ tall and had no over- 
story leaf area. The mostly herbaceous understory contained $85 \pm 52 \mathrm{~g} \mathrm{C} \mathrm{m}^{-2}$ at NC3.

Both NC flux towers are equipped with similar instrumentation, and biophysical data are collected routinely. These measurements are described below. This study focuses on data collected during the 2013 growing season, starting after the launch of Landsat 8 on 11 February 2013 and continuing until 8 November 2013.

\subsection{Micrometeorological and land management data}

At both $\mathrm{NC} 2$ and NC3, energy fluxes were measured using an open-path eddy covariance system, which includes a CSAT3 three-dimensional sonic anemometer (Campbell Scientific instrument - CSI, Logan, UT, USA ${ }^{1}$ ), a CR5000 data logger (CSI), an infrared gas analyzer (IRGA, Model LI7500, LI-COR, Lincoln, NE, USA) and a relative humidity and air temperature sensor (model HMP-45C; Vaisala Oyj, Helsinki, Finland) (Sun et al., 2010). Soil heat flux was measured at NC2 with three heat flux plates (model HFT3, CSI, Logan, UT, USA) at the depth of $2 \mathrm{~cm}$. The soil heat flux plates were placed in three contrasting microsites - one in a row of trees, in relative shade, another between rows in a mostly open environment and one about halfway in between. Measurements of $G$ at the NC3 site are not available for 2013 due to an instrument failure. Net radiation was measured with four-component net radiometers (Kipp \& Zonen CNR-1, Delft, the Netherlands) at each of the two towers. Precipitation was measured by two tipping bucket types of rain gages (TE-525, CSI; Onset data-logging rain gage, Onset Computer Corporation, USA).

Flux observations at $30 \mathrm{~min}$ time steps were quality checked, as judged by atmospheric stability and flux stationarity (Noormets et al., 2008). The 30 min data were then gap filled using the monthly regression between observed and potential ET models created from good quality observed data. The energy imbalance problem was checked and the average closure ratio of the $30 \mathrm{~min}$ dataset at the NC2 site was 0.88 during daytime when net radiation was larger than 0 . Since there were no soil heat flux observations at the NC3 site, there was no closure information and the observed latent heat was used to compare with the simulated data. The 30 min energy fluxes during the daytime were summed up to get daily energy fluxes for validation.

Stand age maps and tree planting history for the study area were obtained from the Weyerhaeuser Company. The stand age ranges from 1 to 89 years, with most stands under 30 years of age. Since this information is proprietary, the stand age maps cannot be displayed; however, these data

\footnotetext{
${ }^{1}$ The use of trade, firm, or corporation names in this article is for the information and convenience of the reader. Such use does not constitute an official endorsement or approval by the United States Department of Agriculture or the Agricultural Research Service of any product or service to the exclusion of others that may be suitable.
}

were used statistically to assess the relationships between water use and stand age. A $60 \mathrm{~m}$ buffer inside the edge of each field was applied to exclude the pixels mixed with roads or other fields. All the other pixels were used to assess the relationships between water use and stand age.

\subsection{ALEXI/DisALEXI model inputs}

The ET estimation process involves fusion of data from three major geostationary and polar-orbiting satellite systems: GOES, MODIS and Landsat. In addition, each ET retrieval pulled meteorological inputs (air temperature, wind speed, vapor pressure, atmospheric pressure and insolation) from a common gridded dataset, generated at hourly time steps and relatively coarse spatial resolution $(32 \mathrm{~km})$ as part of the North American Regional Reanalysis (NARR).

LST data from the GOES imager instruments were used to run ALEXI over the continental US for 2013 at $4 \mathrm{~km}$ resolution (Anderson et al., 2007a). In addition, MODIS (4-day) LAI products (MCD15A3) were aggregated from 1 to $4 \mathrm{~km}$ and interpolated to daily scale using the smoothing algorithm developed by Gao et al. (2008). LAI is used to estimate $f(\varnothing)$ for Eq. (1), to compute radiation transmission to the soil surface and to assign land cover class-dependent vegetation heights for roughness parameterization (see Anderson et al., 2007a).

MODIS products used in the MODIS disaggregation include instantaneous swath LST (MOD11_L2; Wan et al., 2004), geolocation data (MOD03), NDVI (MOD13A2; Huete et al., 2002), LAI (MCD15A3; Myneni et al., 2002), albedo (MCD43GF; Schaaf et al., 2010; Sun et al., 2017) and land cover (MCD12Q1; Friedl et al., 2002). The LST swath data, at $1 \mathrm{~km}$ spatial resolution, were converted to geographic coordinates using an interactive data language (IDL)-based MODIS reprojection tool. The NDVI product $(1 \mathrm{~km}$ spatial resolution) is produced at 16-day intervals, LAI $(1 \mathrm{~km})$ at 4 days and albedo $(1 \mathrm{~km})$ at 8 days. All data were quality checked using a data quality filter. The MODIS NDVI, LAI and albedo data were bilinearly interpolated to estimate daily values. MODIS LST was sharpened using NDVI to reduce the off-nadir pixel smearing effect.

Landsat 8 thermal infrared and shortwave surface reflectance data from 2013 used to run DisALEXI were obtained from USGS. Eight relatively cloud-free (>75\%) Landsat scenes (path 14 and row 35) and clear conditions over the tower site were available during the 2013 growing season, including one Landsat 7 scene and seven from Landsat 8 (Table 1). Landsat-scale LAI was retrieved from Landsat shortwave surface reflectance data using MODIS LAI products as reference (Gao et al., 2012a). LST was sharpened to $30 \mathrm{~m}$ using the blue, green, red, near infrared, SWIR1 and SWIR2 bands (refer to Sect. 2.2.1 for more details about Landsat LST sharpening).

Land cover type was used in both the Landsat and MODIS disaggregation to set pixel-based vegetation parameters in- 


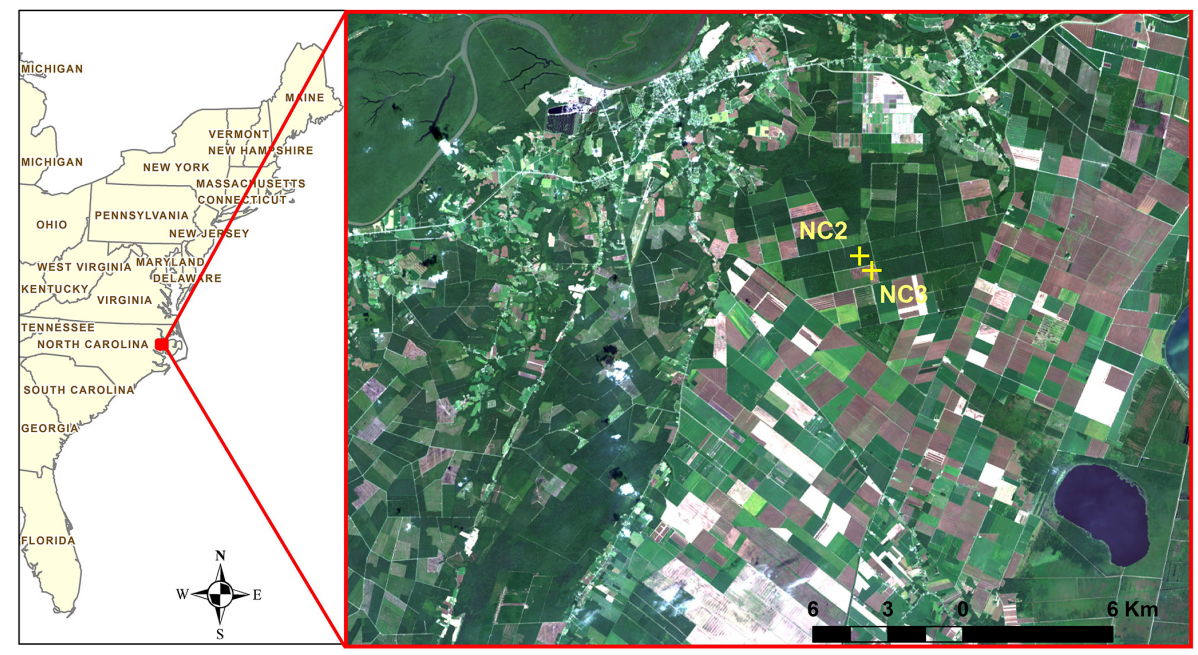

Figure 3. A Landsat 8 true color image (5 September 2013) showing the North Carolina study area. The yellow crosses indicate the location of the NC2 and NC3 flux towers.

Table 1. Landsat overpass dates used in the study.

\begin{tabular}{lrrrrrrrr}
\hline Sensor & Landsat 7 & Landsat 8 & Landsat 8 & Landsat 8 & Landsat 8 & Landsat 8 & Landsat 8 & Landsat 8 \\
\hline DOY & 96 & 104 & 136 & 152 & 200 & 248 & 312 & 328 \\
\% Cloudiness & 0.1 & 0 & 16.4 & 5.1 & 23.8 & 0.3 & 0.1 & 0.1 \\
\% SLC gap & 37 & n/a & n/a & n/a & n/a & n/a & n/a & n/a \\
\hline
\end{tabular}

n/a means not applicable.

cluding seasonal maximum and minimum vegetation height (used in the surface roughness formulations), leaf size and leaf absorptivity in the visible, near-infrared (NIR) and TIR bands following Cammalleri et al. (2013). For DisALEXI using Landsat, the $30 \mathrm{~m}$ national land cover dataset (NLCD) for 2006 (Fry et al., 2011; Wickham et al., 2013) was used. For the MODIS disaggregation, the NLCD was resampled to $1 \mathrm{~km}$ resolution using the dominant class in each pixel.

\section{Results}

\subsection{Performance of the Landsat gap-filling algorithm}

Examples of results from the Landsat gap-filling method are shown in Figs. 4 and 5. For DOY 96 (Fig. 4), L7 SLC stripes and also a few cloudy areas were filled by combining the direct Landsat retrieval (left panel) with the STARFM ET prediction for DOY 96 generated using a Landsat-MODIS image pair from DOY 104. The cloudy areas in DOY 200 (Fig. 5) were filled using a Landsat-MODIS pair from DOY 152. In each case, the size of the overlapped moving window was $420 \mathrm{~m}$ by $420 \mathrm{~m}$. This means that contiguous gaps larger than the window were not filled since there were not enough candidate pixels to create the statistical relationship needed between the direct Landsat retrieval and
STARFM ET. The white rectangular box located in the northeast area of both figures contains no data because more than $40 \%$ of Landsat pixels within the $4 \mathrm{~km}$ ALEXI ET pixel were affected by a large water body.

In each of these cases, the spatial patterns within missing regions in the direct retrievals appear reasonably reconstructed with the ET gap-filling method, with no obviously patchy artifacts in the gap-filled ET images. Even linear structures were restored: for example, roads and field boundaries. The gap-filling method works even better when the small or linear objects are very different from surrounding pixels. The choice of moving window size can affect the gapfilling results and may require scene-based adjustment, with the need to balance the risk of inappropriate candidate pixel selection if the window is too large, or a lack of candidate pixels if the window is too small.

Figure 6 shows a synthetic study used to assess the accuracy of the gap-filling procedure. Here, a direct Landsat ET retrieval for DOY 152 was artificially masked using SLC stripes from DOY 96. The final panel shows the gapfilled image. Comparing the original values with the gapfilled values yields an $R^{2}$ of 0.89 and a mean absolute error (MAE) of $-0.01 \mathrm{~mm} \mathrm{day}^{-1}$, with the average of original values as $5.81 \mathrm{~mm} \mathrm{day}^{-1}$ and the average of gap-filled values as $5.80 \mathrm{~mm} \mathrm{day}^{-1}$. 

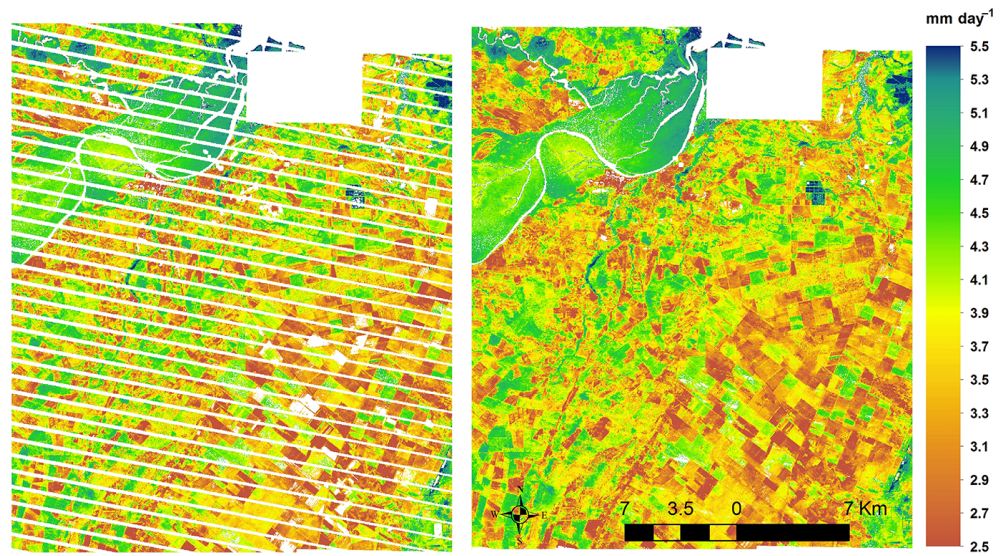

Figure 4. Example of gap-filling SLC-off stripes in a Landsat 7 ET image for DOY 96, 2013. The left image is Landsat-retrieved ET with stripes, while the right image has been gap filled using the method described in Sect. 2.2.3.
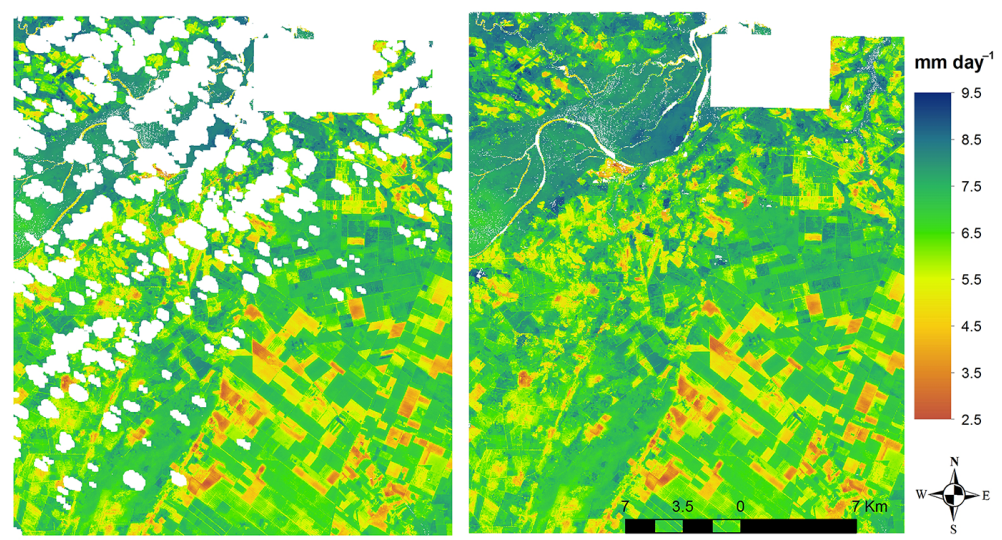

Figure 5. Example of gap-filling cloudy regions in a Landsat 8 ET image for DOY 200. The left image is Landsat-retrieved ET with clouds masked using the Fmask data layer and the right image has been processed through the Landsat gap-filling method.

The gap-filling method described in Sect. 2.2.3 relies on the inputs from both the original Landsat ET and the STARFM predictions, which in turn rely on a filled MODIS image on the target date as well as a MODIS-Landsat image pair on a surrounding date. If the Landsat image in the input pair also has gaps, additional pairs can be used to iteratively fill the target image.

\subsection{Evaluation of daily ET retrievals from DisALEXI at the flux tower sites}

Modeled and measured instantaneous and daytime integrated surface energy fluxes on Landsat overpass dates are compared in Fig. 7, demonstrating good correspondence. Statistical performance metrics for each flux component for both sites are shown in Table 2, including MAE, root mean square error (RMSE) and mean bias error (MBE). The model performance for each flux is similar between sites, with somewhat lower errors obtained for the clear-cut site (NC3). The latent heat observed at the NC2 site is higher than that at NC3 with or without closure enforcement. As mentioned earlier, closure could not be assessed at NC3 due to failure among the soil heat flux instrumentation. At NC2, closure by residual resulted in an increase in observed ET by approximately $12 \%$ on average.

Time series of ALEXI ET ( $4 \mathrm{~km})$, Landsat ET retrieved on Landsat overpass dates and Landsat-MODIS fused ET (both at $30 \mathrm{~m}$ resolution) are compared in Fig. 8 with ET observed at both the NC2 and NC3 sites from DOY 50 to 330. In addition, daily ET values generated using a simple Landsat-only interpolation scheme are shown for comparison. These were generated using the MODIS and ALEXI gap-filling technique described in Sect. 2.2, conserving the ratio of actual-toreference ET between Landsat overpass dates. Metrics of statistical performance at daily to seasonal timescales are listed in Table 3.

Figure 8 highlights the value of disaggregation to the tower footprint scale for the purposes of model validation. For NC2, ALEXI $4 \mathrm{~km}$ fluxes agree well with tower observations, suggesting that the tower footprint at $\mathrm{NC} 2$ is reasonably rep- 

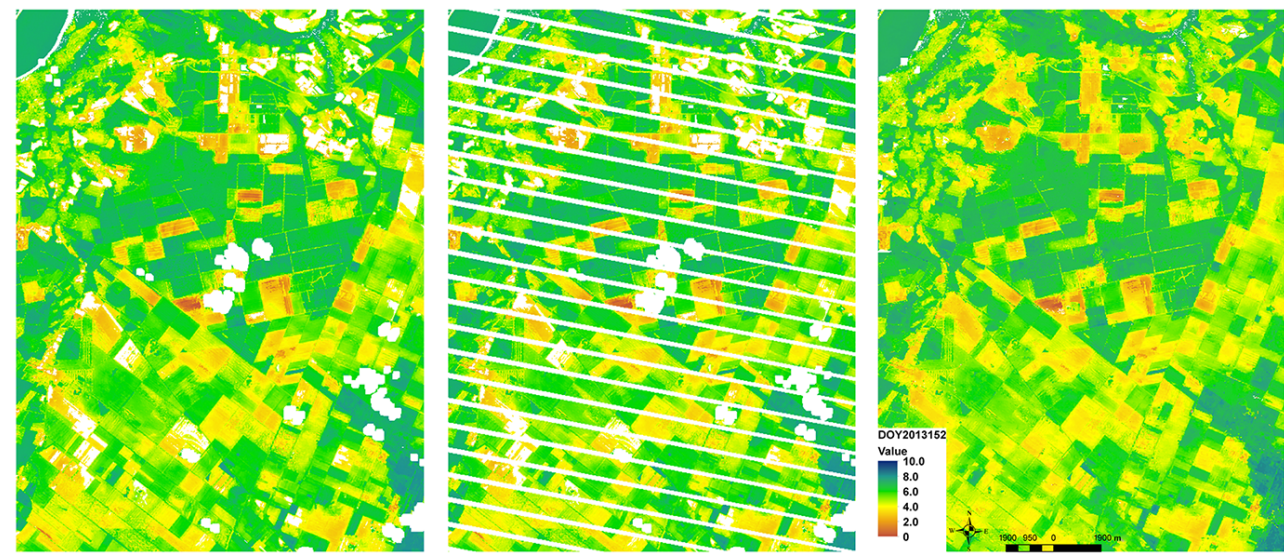

Figure 6. Comparison between the original Landsat ET retrieval for DOY 152 (left panel), an artificially gapped version, imposing SLC gaps from DOY 96 (middle panel), and the gap-filled map (right panel).
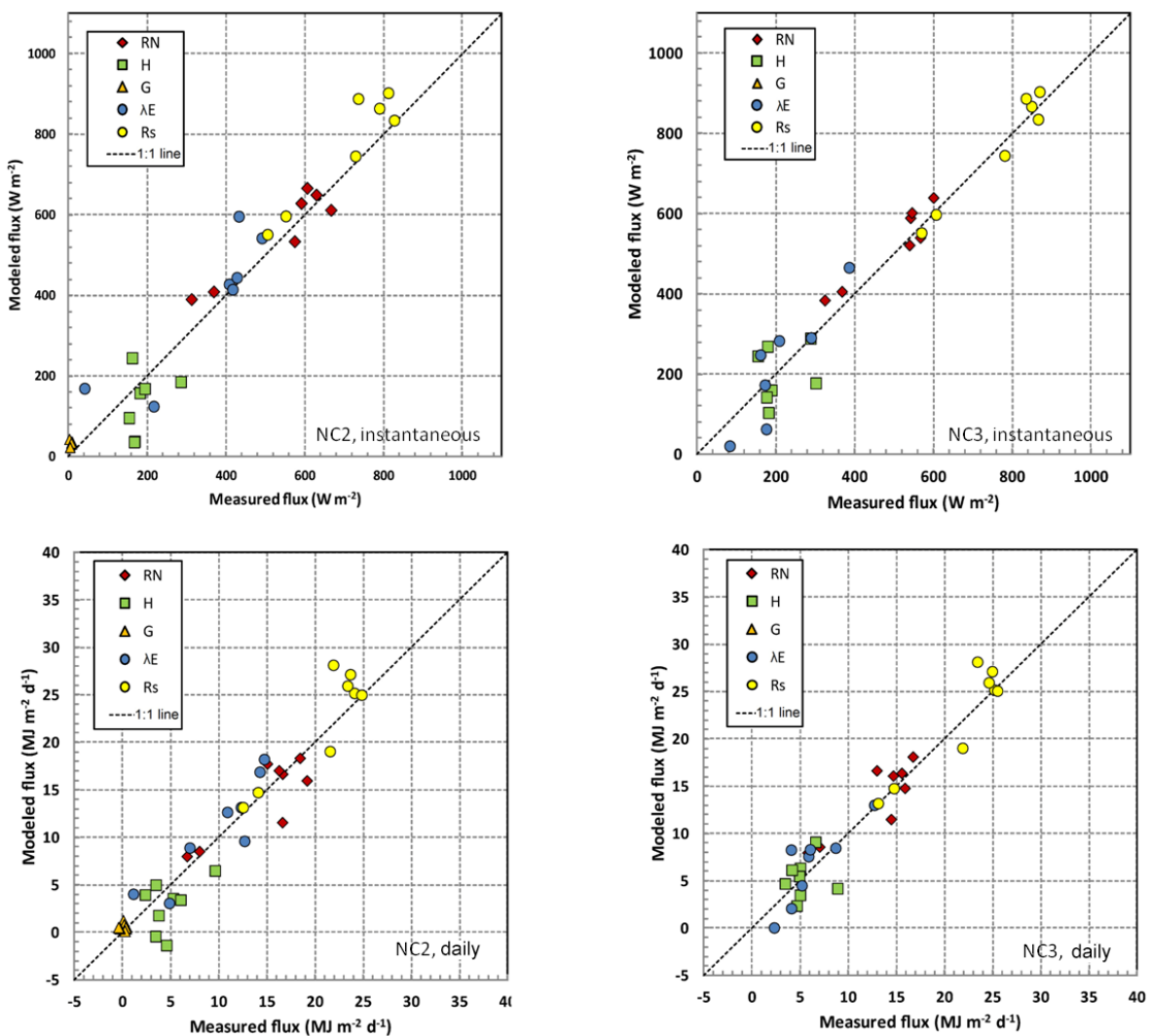

Figure 7. Scatterplot of modeled and measured instantaneous (top row panels) and daily surface fluxes (bottom row panels) on Landsat overpass dates for NC2 (left column panels) and NC3 (right column panels) flux tower sites.

resentative of the surrounding $4 \mathrm{~km}$ ALEXI pixel area. The disaggregated $30 \mathrm{~m}$ fluxes are also similar to both ALEXI and observations at this site. At NC3, however, the $4 \mathrm{~km}$ ALEXI fluxes are notably higher than the observed ET, while the disaggregated fluxes are comparable. The NC3 tower site is not representative at the ALEXI pixel scale, and disaggregation to the tower footprint scale is required to account for local sub-pixel heterogeneity. Even at $1 \mathrm{~km}$ resolution, the MODIS retrieval accuracy was degraded at NC3 in comparison with the Landsat-scale retrievals (Table 3). Recall that NC3 was recently clear-cut with surrounding areas still comprised by more mature forest stands. With the $4 \mathrm{~km}$ spatial resolution, ALEXI ET is able to capture the ET status of the major land cover type (i.e., mature forest), but not the particular patch 

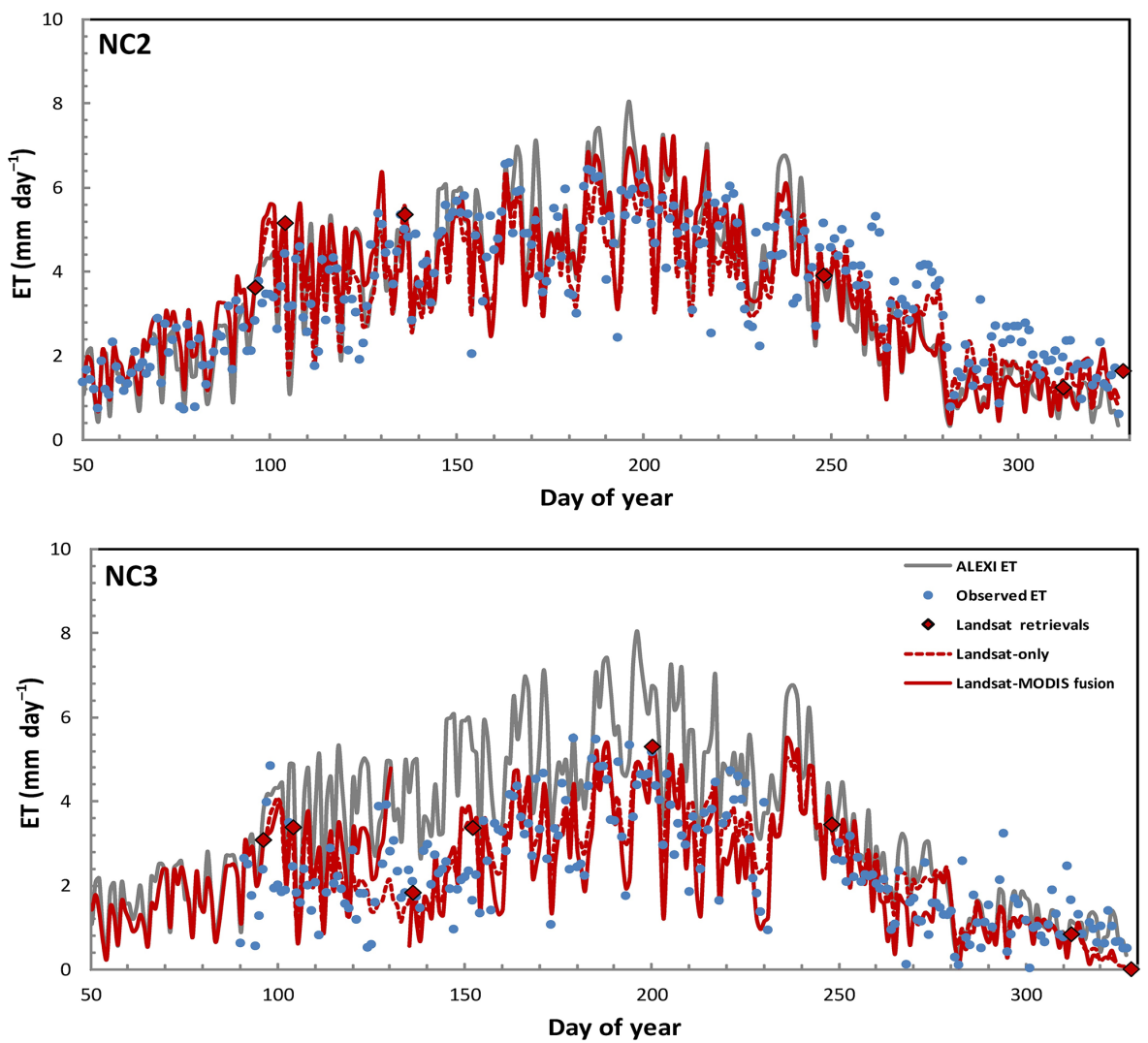

Figure 8. Comparison of time series of ALEXI ET ( $4 \mathrm{~km})$, observed ET, Landsat ET retrieved on Landsat overpass dates, Landsat-only interpolated ET and Landsat-MODIS fused ET for the NC2 site (and NC3, bottom panel) sites in 2013.

of land where the NC3 tower is located. This underscores the need for appropriate spatial resolution when comparing modeled with observed fluxes, especially for the more heterogeneous land surfaces (e.g., Anderson et al., 2004).

Overall, the performance of the two Landsat retrievals (STARFM and Landsat only) are comparable between sites, with RMSE at daily time steps of $\sim 0.8$ to $1.0 \mathrm{~mm} \mathrm{day}^{-1}$ and MAE of 0.6 to $0.8 \mathrm{~mm} \mathrm{day}^{-1}$ (19-30\% of the mean observed ET). At monthly time steps, performance improves to 11$14 \%$, due to averaging of random errors - including errors in daily insolation forcings from the NARR meteorological dataset. Fluxes are somewhat underestimated at the end of the growing season at each site due largely to the Landsat retrieval on DOY 312. This highlights the importance of good temporal sampling at the Landsat scale - an additional Landsat scene around DOY 270 during the prolonged gap in coverage may have improved the seasonal water use estimates. A small negative mean model bias is observed for both sites, due primarily to underestimation at the end of growing season of the Landsat retrieval on DOY 312. This is also the reason that Landsat-only interpolated ET performs slightly better than STARFM. More details about the comparison of the two Landsat retrievals can be found in the Discussion section.
The seasonal cumulative ET at $\mathrm{NC} 2$ and $\mathrm{NC} 3$, calculated for DOY 90-330 from both the observed ET and the Landsat-MODIS fused time series, is shown in Fig. 9. For $\mathrm{NC} 3$, the accumulation does not include values of modeled or measured ET during the period DOY 232-248 when flux tower data were not available, so these values do not represent the total seasonal water use at this site. The modeled cumulative water use on DOY 330 agrees with the observed values to within $-0.9 \%$ at $\mathrm{NC} 2$ and $0.4 \%$ at $\mathrm{NC} 3$. Overall, the modeled and measured cumulative ET curves agree well throughout the growing season, indicating the remote sensing method has utility for water use management and assessment at subseasonal timescales.

\subsection{Spatiotemporal variability in seasonal water use}

\subsubsection{ET variations with land cover}

Figure 10 shows the land cover types over the study area as described in the NLCD from $2006^{2}$. The major classes represented in the NLCD over the study area include crop land

\footnotetext{
${ }^{2}$ Note: an updated NLCD map for 2011 was published after the study was implemented, but there was no notable change in land cover types over the study area in comparison with NLCD2006.
} 


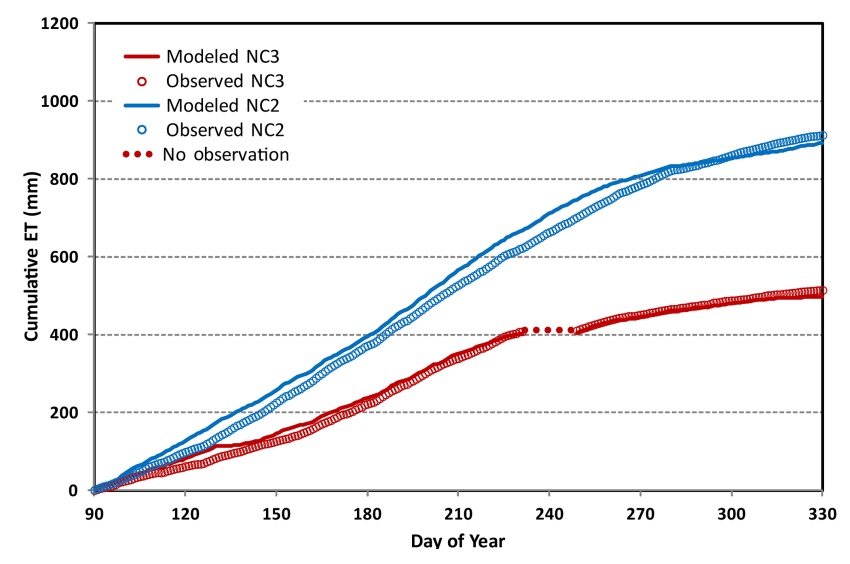

Figure 9. Comparison between the modeled and observed seasonal cumulative ET at NC2 and NC3 during 2013.

(including corn, cotton and soybeans), forest and woody wetland. The land cover in many plots within the Parker Tract plantation, including the NC2 site, was classified as woody wetland rather than evergreen forest. This misclassification, however, had little impact on the model ET estimates at NC2 due in part to the normalization constraint imposed by the $4 \mathrm{~km}$ ALEXI ET output.

Time series maps of monthly and cumulative ET in Fig. 11 over the study area exhibit spatiotemporal water use patterns that are related to land cover type (Fig. 10). The relatively high rates of ET during midseason in the riparian and more densely forested regions are readily apparent. Water use patterns in the cultivated agricultural areas reflect the diversity of crops and water management strategies. Within the Parker Tract plantation, a few fields with persistently low ET may be fresh clear cuts, possibly with a layer of slash to inhibit emergence of new vegetation. In the summer of 2014, after the slash has been collected and piled, these plots may appear more like the recent clear cut near NC3.

Seasonal ET time series were developed for five generalized land cover classes (crop land, natural forest, woody wetland, mature plantation and young plantation) to assess variability in water use with land use/land cover type in the study area. The term "natural forest" is used to describe unmanaged mixed forested areas within the study domain. "Mature plantation" refers to managed stands of loblolly pine within the Parker Tract with ages ranging from 10 to 20 years, while "young plantation" indicates stand ages less than 3 years. Figure 12 shows the time series of modeled field-scale ET averaged from 10 randomly sampled pixels associated with each generalized land cover class for 2013. For the woody wetland class, care was taken to select pixels that were correctly classified by visual inspection of Google Earth imagery. A 7-day moving average was applied to the modeled daily ET to reduce noise and facilitate visual comparison.

Pixels classified as woody wetland, natural forest, agriculture and mature plantation generally showed higher ET

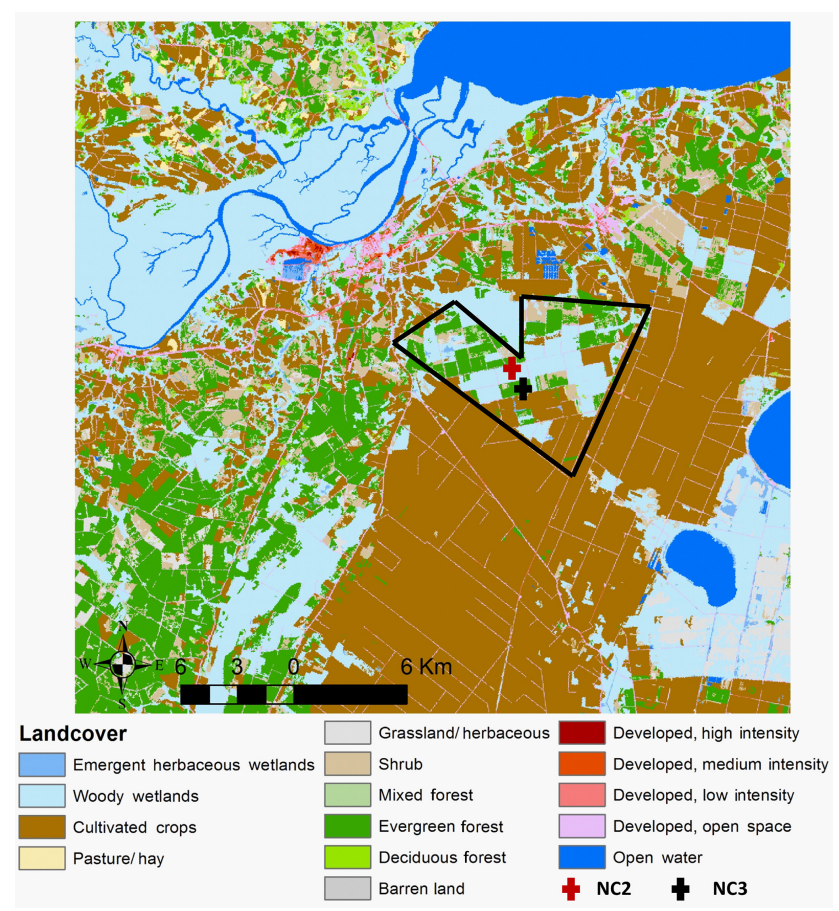

Figure 10. Land cover types over the study area from NLCD 2006. Area in the black outline is the plantation area.

than did the young plantation pixels. Water use in the woody wetland areas was the highest among all the different land cover types but was similar to natural forest and mature managed forest during the peak growing season. The seasonal cumulative ET from these five land cover types is shown in Fig. 13. The woody wetlands tended to have higher seasonal ET than the other three classes, slightly exceeding that of natural forest and mature pine plantations. Modeled water use in crop lands exceeded that in young plantation stands, resulting from relatively higher LAI and lower LST observed over the cropped areas.

Figure 14 shows the average cumulative ET between DOY 50 and 330 associated with the five different land cover types, computed from the 10 random samples per class, and the black bars represent the standard deviation among the samples. Natural forests showed the lowest variability in ET $(30 \mathrm{~mm})$, while the woody wetland and mature plantation pixels had the highest standard deviations $(74$ and $73 \mathrm{~mm}$, respectively). The high variability in the latter classes may reflect both management effects and misclassification. Crop lands and young forest plantations showed moderate variability in water use, with standard deviations of 64 and $50 \mathrm{~mm}$, respectively. In terms of coefficient of variation in water use across the modeling domain, the crops and young plantation classes are relatively high at $7.1 \%$, compared to natural forest at $2.8 \%$. Crops and young plantations also have higher coefficients of variation in LAI than other land cover types, 
leading to larger variability in water use demand through transpiration.

Because the two-source land-surface representation in DisALEXI also provides estimates of the evaporation $(E)$ and transpiration $(T)$ components of ET, the model output can also be used to assess variability in $E$ / $T$ partitioning between land cover types and through the season (Fig. 15). In general, soil evaporation losses account for a higher percentage of total ET early in the season, after the spring rains but before the canopies have completely leafed out. On average through the season, the $E / T$ ratio is highest for crop lands, young plantations and woody wetlands. This is reasonable given the lower leaf area characteristic of these classes and the abundant substrate moisture in the case of woody wetlands. Partitioning to $T$ is maximized during the peak growing season (DOY 152, 200 and 248) for all the land cover types. Natural forests and mature plantations tend to have higher rates of transpiration than other land cover types.

\subsubsection{ET variations with LAI}

Many forest hydrology models ( $\mathrm{Lu}$ et al., 2003; Scott et al., 2006; Sun et al., 2011a) assume seasonal ET is well correlated with LAI. This assumption was tested over the set of points chosen randomly from different land cover types. Sample points from mature plantations, young plantations and crop lands were all located in drained areas, while sample points from natural forest and woody wetland were in undrained areas. However, LAI values from the sample points were not affected by drainage conditions. High LAI values were obtained from both drained mature plantations and undrained natural forest, while relatively low LAI values were from both drained young plantations and undrained woody wetlands. Figure 16 shows that some (but not all) variability in ET, as predicted by the fusion estimates, is explained by variability in average LAI over the prediction time period $\left(R^{2}=0.59\right)$. These results indicate that, in 2013 , increasing LAI added up to $350 \mathrm{~mm}$ of seasonal water use on top of nearly $800 \mathrm{~mm}$ from the soil evaporation contribution. The high rates of ET at low LAI are reasonable, given that the study area was fairly wet during 2013 due to plenty of precipitation and shallow water tables.

\subsubsection{ET variations with plantation stand age}

Within the managed pine plantation at Parker Tract, we also examined variations in seasonal water use with stand age (Fig. 17). This has relevance to forest management practices and their impacts on the water yield of the watershed, which is the difference between precipitation and evapotranspiration over the long term. Higher water yield translates to higher streamflow available for downstream use. Many forest management practices, for example, thinning and reforestation, need to consider the influence of stand age on the hydrological response.

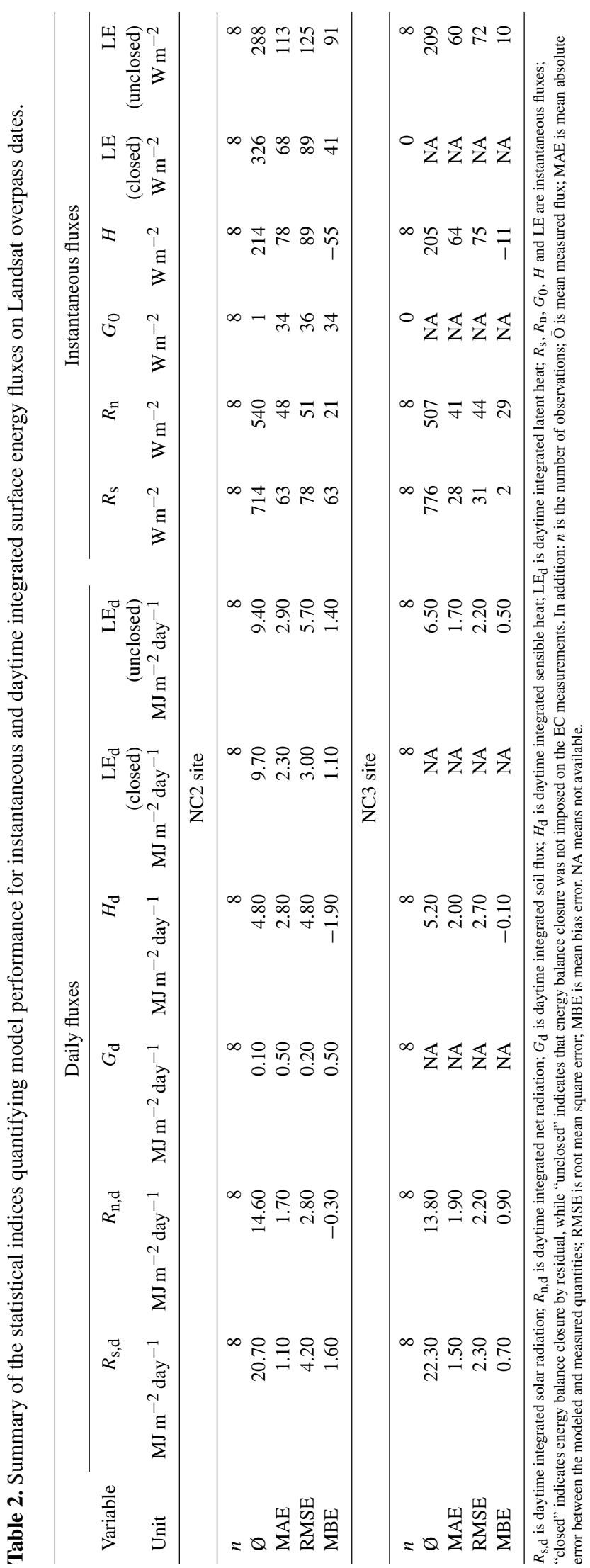

Hydrol. Earth Syst. Sci., 21, 1017-1037, 2017 


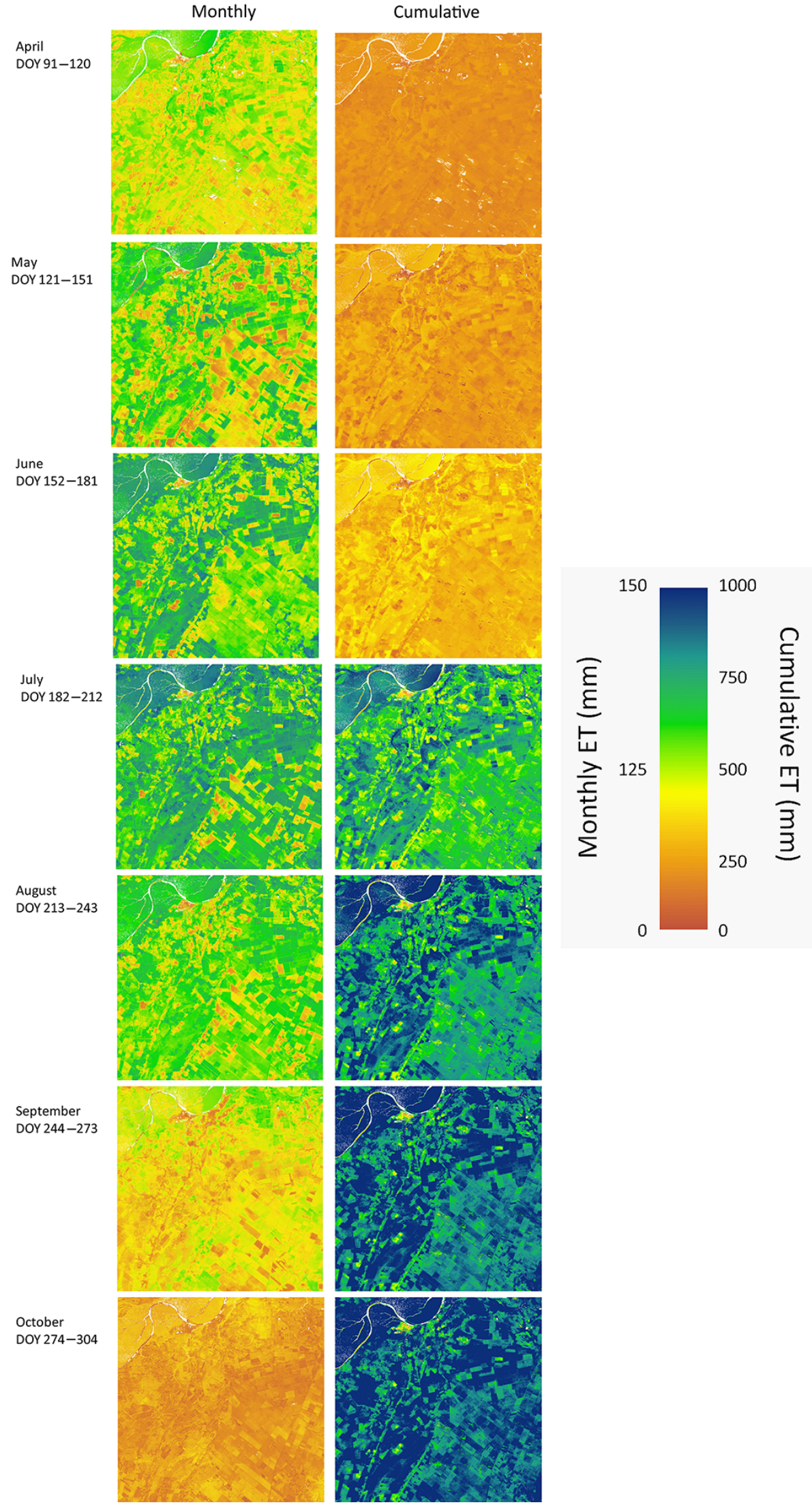

Figure 11. Spatial patterns of monthly cumulative ET (left column panels) from April to October, and cumulative ET on the end day of each month over the study area. 


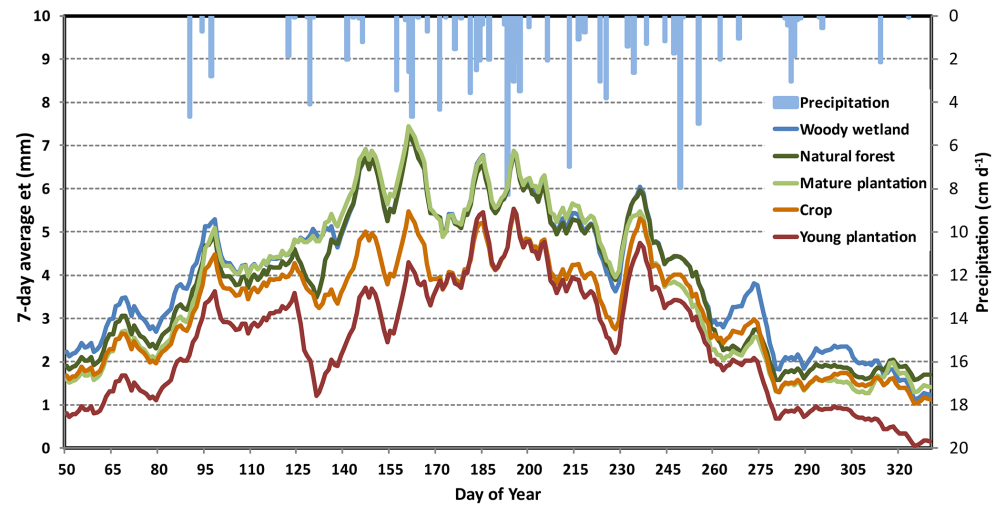

Figure 12. Time series of modeled plot-scale ET (daily values smoothed with a 7-day moving average) associated with different land cover types.

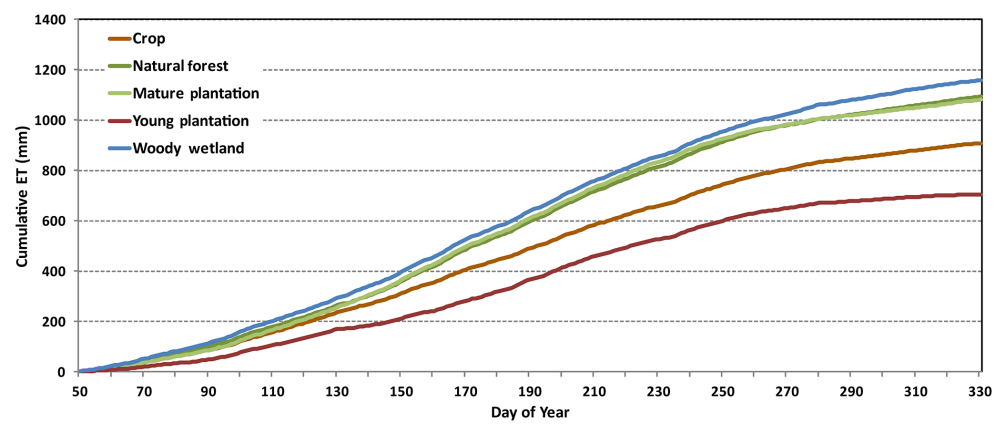

Figure 13. Seasonal cumulative ET for different land cover types.

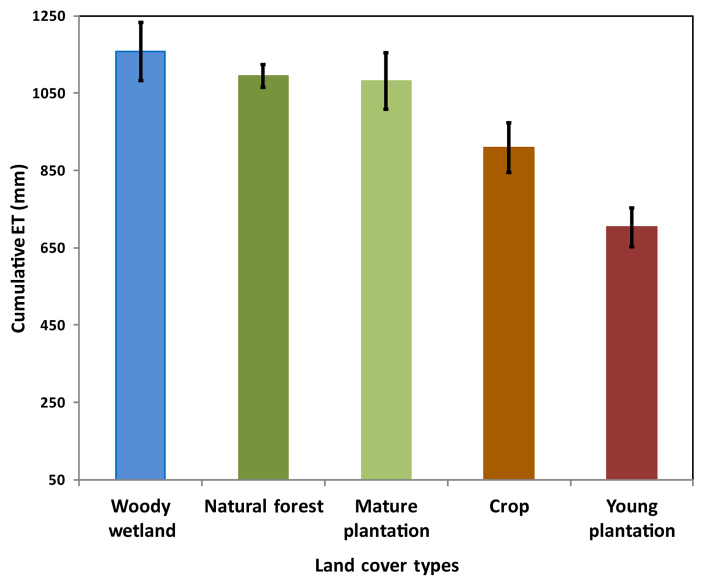

Figure 14. Average cumulative ET at DOY 330 in 2013 over different land cover types, and standard deviations within the sample populations (the black bar).

Plotting cumulative ET at DOY 330 from various sites against stand age (Fig. 17), there is a clearly positive linear relationship between water use and stand age for the younger stands, between a few years old and around 20 years old $\left(R^{2}\right.$ is 0.82 ). As the stand age increases, more water is used as ex-

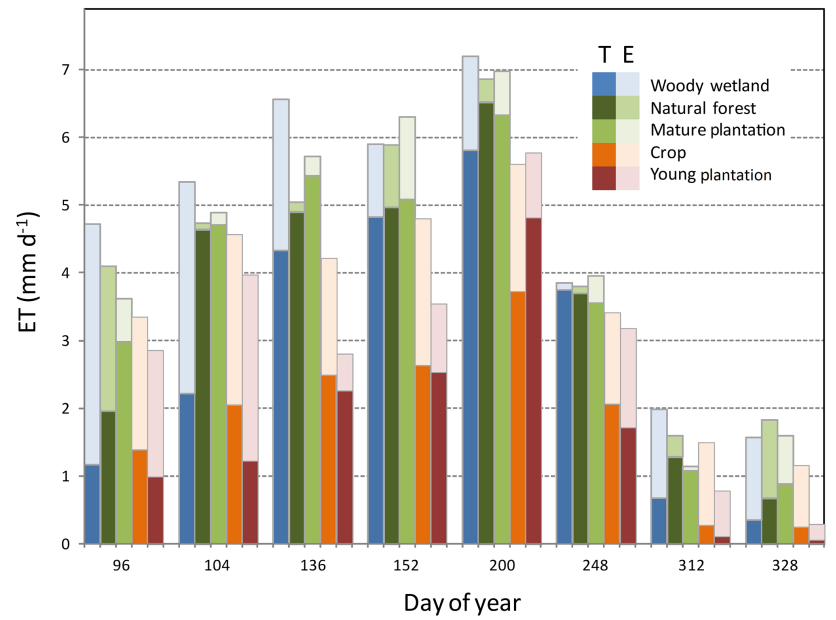

Figure 15. Average evaporation $(E)$ and transpiration $(T)$ components of ET for five land cover types on Landsat overpass days.

pected to sustain larger amounts of biomass. Differences in seasonal cumulative ET curves for different stand ages begin to significantly diverge after DOY 130 - around the middle of May (not shown). When the stand matures beyond 20 years, 
Table 3. Statistical metrics describing comparison of retrieved ET time series with tower observations at NC2 and NC3 at daily and monthly time steps, as well as cumulative values over the study period (DOY 50-330).

\begin{tabular}{|c|c|c|c|c|c|c|c|c|}
\hline \multirow{2}{*}{$\begin{array}{l}\text { Site } \\
\text { Index }\end{array}$} & \multicolumn{4}{|c|}{ NC2 site } & \multicolumn{4}{|c|}{ NC3 site } \\
\hline & STARFM & $\begin{array}{r}\text { Landsat } \\
\text { only }\end{array}$ & $\begin{array}{l}\text { MODIS } \\
\text { smoothed }\end{array}$ & ALEXI & STARFM & $\begin{array}{r}\text { Landsat } \\
\text { only }\end{array}$ & $\begin{array}{l}\text { MODIS } \\
\text { smoothed }\end{array}$ & ALEXI \\
\hline & \multicolumn{4}{|c|}{ Daily } & \multicolumn{4}{|c|}{ Daily } \\
\hline$n$ & 281 & 216 & 281 & 281 & 223 & 199 & 223 & 223 \\
\hline $\operatorname{MAE}\left(\mathrm{mm} \mathrm{day}^{-1}\right)$ & 0.80 & 0.64 & 0.66 & 0.85 & 0.83 & 0.70 & 2.00 & 1.45 \\
\hline RMSE (mm day $\left.{ }^{-1}\right)$ & 0.99 & 0.83 & 0.85 & 1.04 & 1.02 & 0.88 & 2.27 & 1.84 \\
\hline $\operatorname{MBE}\left(\mathrm{mm} \mathrm{day}^{-1}\right)$ & -0.03 & -0.29 & -0.10 & -0.11 & -0.05 & 0.10 & 1.96 & 1.31 \\
\hline \multirow[t]{2}{*}{$\operatorname{RE}(\%)$} & 27.9 & 19.2 & 22.0 & 28.0 & 30.6 & 25.1 & 85.0 & 56.0 \\
\hline & \multicolumn{4}{|c|}{ Monthly } & \multicolumn{4}{|c|}{ Monthly } \\
\hline$n$ & 12 & 8 & 12 & 12 & 10 & 8 & 10 & 10 \\
\hline $\operatorname{MAE}\left(\mathrm{mm} \mathrm{day}^{-1}\right)$ & 0.41 & 0.36 & 0.48 & 0.44 & 0.23 & 0.33 & 1.61 & 1.06 \\
\hline $\operatorname{RMSE}\left(\mathrm{mm} \mathrm{day}^{-1}\right)$ & 0.53 & 0.39 & 0.58 & 0.54 & 0.29 & 0.36 & 1.82 & 1.33 \\
\hline $\operatorname{MBE}\left(\mathrm{mm} \mathrm{day}^{-1}\right)$ & 0.00 & -0.25 & -0.11 & -0.15 & -0.01 & 0.16 & 1.61 & 1.06 \\
\hline \multirow[t]{2}{*}{$\operatorname{RE}(\%)$} & 13.6 & 12.1 & 16.1 & 14.8 & 10.9 & 15.5 & 76.3 & 50.1 \\
\hline & \multicolumn{4}{|c|}{ Study period } & \multicolumn{4}{|c|}{ Study period } \\
\hline$n$ & 1 & 1 & 1 & 1 & 1 & 1 & 1 & 1 \\
\hline $\operatorname{MAE}\left(\mathrm{mm} \mathrm{day}^{-1}\right)$ & 0.03 & 0.04 & 0.10 & 0.11 & 0.01 & 0.12 & 1.88 & 1.26 \\
\hline $\operatorname{MBE}\left(\mathrm{mm}\right.$ day $\left.^{-1}\right)$ & -0.03 & 0.04 & -0.10 & -0.11 & 0.01 & 0.12 & 1.88 & 1.26 \\
\hline RE $(\%)$ & 0.9 & 1.3 & 2.7 & 3.2 & 0.4 & 5.2 & 81.0 & 54.3 \\
\hline
\end{tabular}

RE is relative error, which is calculated by dividing MAE by observed average ET.

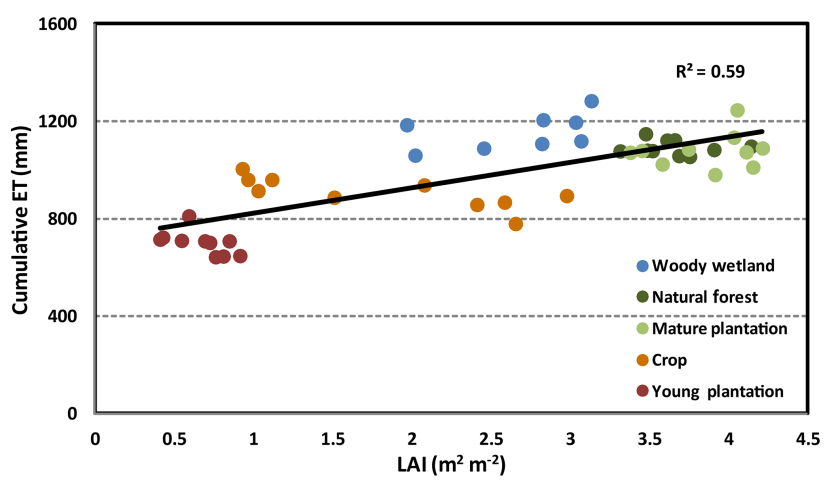

Figure 16. Modeled cumulative ET from DOY 50 to DOY 330 as a function of LAI.

the water usage tends to plateau and may actually decrease slightly for stands with trees older than 75 years.

\section{Discussion}

\subsection{Utility of TIR-based data fusion as a daily ET estimation method}

In this study, the STARFM modeling approach applied over a full growing season resulted in a relative errors in ET at the

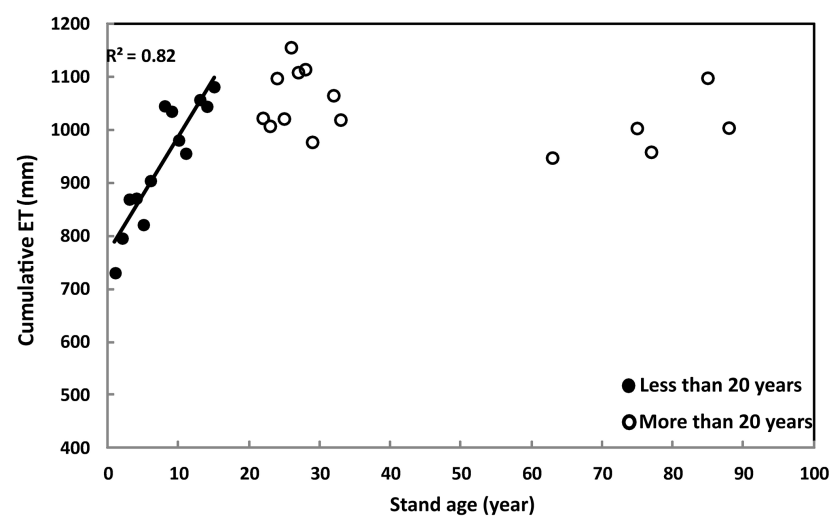

Figure 17. Modeled cumulative ET at DOY 330 as a function of stand age.

daily time step of $28 \%$ for the mid-rotation pine plantation site and $31 \%$ for the clear-cut site, and errors of $13.6 \%$ at the monthly time step. The accuracy of these results is comparable with earlier studies applying the STARFM ET data fusion approach. Over rain-fed and irrigated corn and soybean sites in central Iowa (IA), STARFM yielded a relative error of about $11 \%$ over eight flux towers (Cammalleri et al., 2013). When STARFM was applied to the Bushland, TX, the daily ET estimation had a relative error of $26.6 \%$ for ir- 
rigated area and $27 \%$ for rain-fed area (Cammalleri et al., 2014). For a study area near Mead, NE, the relative error was $20.8 \%$ for irrigated crops and $25.4 \%$ for rain-fed crops (Cammalleri et al., 2014). Semmens et al. (2015) estimated daily Landsat-scale ET over California vineyards with relative error of $18 \%$ for an 8-year-old vineyard and $23 \%$ for a 5-year-old vineyard.

In the current study, we found that STARFM yielded similar or marginally lower accuracy than did a simple Landsatonly ET interpolation scheme in estimating fluxes between Landsat overpasses. This is in contrast to results from Cammalleri et al. (2013), who found that STARFM significantly outperformed the Landsat-only approach in comparison with flux measurements acquired over rain-fed crops in central IA during the soil moisture experiments in 2002 (SMEX02). There may be several factors that influence the potential value added by STARFM that can be deduced from this comparison. One factor may be climate and moisture status within the target modeling domain. During the first part of SMEX02 experiment, conditions were becoming quite dry and the crops - particularly the corn fields - were becoming notably stressed, exhibiting leaf curl near the field edges. A rainfall event near the beginning of July (between Landsat overpasses) significantly relieved the crop stress and greatly impacted soil moisture conditions over the SMEX02 study area (Anderson et al., 2013). In contrast, the climate of the Parker Tract study site studied here was very wet during 2013, and vegetation condition was not water limited. Consequently, as long as other factors do not affect the health of the vegetation (e.g., pest/disease infestation) or large variations do not occur in atmospheric demand (large oscillations in radiation, wind and temperature), the evapotranspiration process will remain near a constant fraction of potential and may be reasonably captured by a simple daily interpolation scheme. At the NC sites studied here, there were no major changes in soil moisture status that were additionally captured by the MODIS ET retrievals. This might not be the case in severe drought years. Another factor to be considered is predominant land cover type. The NC sites are dominated by trees, with deeper rooting systems than perennial crops, and are able to extract water that is available much deeper in the soil profile. This further reduces variability in vegetation response during the study period in comparison with the SMEX02 study.

These two factors are consistent with the assumptions in the Landsat-only interpolation, which assumes the ratio between actual ET and reference ET is smoothly varying over time. However, for rain-fed crop land areas (like the central IA sites) that occasionally go through relatively dry and wet periods, STARFM may be better able to capture time variability in $f_{\text {RET }}$ in response to changing moisture conditions. Despite the limited value added by STARFM over standard methods in this case, Fig. 8 shows that both methods performed very well.
For real-time applications in water management, STARFM can be used to project water use information beyond the date of the last Landsat overpass within some limited time range, assuming MODIS data are available with low time latency. Practical limits to a viable projection time range may vary with site and season and will depend on the rate of change in weighting factors governing the STARFM fusion process.

\subsection{Comparison with prior ET studies over the Parker Tract}

Direct measurements of ET within the Parker Tract study area are only available for pine plantations ( $\mathrm{NC} 2$ and $\mathrm{NC} 3$ AmeriFlux sites) (Sun et al., 2010; Domec et al., 2012). Annual ET rates for the NC2 site reported by Sun et al. (2010) vary from $892 \mathrm{~mm}$ (a dry year, 2007) to $1226 \mathrm{~mm}$ in a normal year (2006). A process-based forest hydrological model (DRAINMOD-FOREST) has been calibrated for the $\mathrm{NC} 2$ eddy flux site using drainage and groundwater table data for the period of 2005-2012. ET estimates by the calibrated model vary from $903 \mathrm{~mm} \mathrm{yr}^{-1}$ in 2008 to $1170 \mathrm{~mm} \mathrm{yr}^{-1}$ in 2006. These reported annual ET rates are consistent with results from the present study, which indicate ET values of 1000-1200 $\mathrm{mm} \mathrm{yr}^{-1}$ for pine plantations established in the 1990s.

Empirical models of ET, operative at the monthly timescale, have been developed for the Parker Tract study area (Sun et al., 2011a) and the accuracy is generally uncertain due to the large variability of climate and ecosystem structure and ET processes in general. For example, Sun et al. (2011a) proposed a general predictive model to estimate monthly ET using reference ET, precipitation and LAI over 13 ecosystems, which included the mid-rotation NC2 site and another clear-cut site (NC1 in AmeriFlux database) also in our study area. The monthly ET estimates from that approach had a relative error of $23 \%$ and a RMSE of $15.1 \mathrm{~mm} \mathrm{month}^{-1}$, while STARFM relative errors from the current study were $13.6 \%$ at the monthly time step - a substantial improvement in accuracy.

\subsection{Water use variations with stand age and land cover type}

Previous studies investigating the relationship between land cover and age of forest stands on water usage mainly focused on the resulting impact on the water balance via impacts on streamflow at the watershed scale (Matheussen et al., 2000; Vertessy et al., 2001; Williams et al., 2012). Matheussen et al. (2000) analyzed the hydrological effects of land cover change in the Columbia River basin and found a significant correlation between hydrological change and the tree maturity in the forested areas. In the current study, we found that water use increased linearly with stand age between 1 and 20 years, then plateaued or decreased with age after about 
20 years. An investigation of mountain ash forests in Victoria, Australia, found that annual ET from a nearly 35-year stand was $245 \mathrm{~mm}$ more than that from a 215-year stand (Vertessy et al., 2001). Similarly, another study of three forest stands, aged 14, 45 and 160 years, found plot transpiration declined from $2.2 \mathrm{~mm}$ per day in the 14-year stand and $1.4 \mathrm{~mm}$ per day in the 45 -year stand to $0.8 \mathrm{~mm}$ per day in the 160-year-old forest (Roberts et al., 2001). In another study, Kuczera (1987) found a rapid decrease of mean annual water yield from a mountain ash forest watershed when stand age increased from 1 year to around 25 years, suggesting greater water use by the older forest stands. Murakami et al. (2000) used a Penman-Monteith-based model to simulate an ETstand age relationship, which also showed a clear upward trend for young forests and a peak in ET at 20 years. The sharp increase of seasonal ET with the increase of stand age from 1 year to around 20 years illustrated in Fig. 17 is consistent with these earlier studies. Plant LAI is closely related to ET (Sun et al., 2011a) and is also an important input in plant physiological and hydrologic/land surface models as well as crop models (Duchemin et al., 2006; Nemani et al., 1993; Tague et al., 2013). As shown in Fig. 16, we also find correlation between cumulative ET and season-average LAI over different land cover types, although LAI explained only $59 \%$ of the modeled variability in ET.

\section{Conclusions}

This study demonstrates the capability of a multiscale data fusion ET model to estimate daily field-scale ET over a forested landscape. Daily ET retrievals over the growing season of 2013, generated at $30 \mathrm{~m}$ spatial resolution, compared well with observed fluxes at AmeriFlux tower sites in a mature pine stand and a recent clear-cut site, demonstrating capability to reasonably capture a range in land-surface conditions within a managed pine plantation. Errors were $29 \%$ at daily time step, $12 \%$ at monthly time step and $0.7 \%$ over the study period.

A new scene gap-filling method was described to maximize the number of Landsat images used for ET retrieval at Landsat scale and will be of benefit in areas with persistent partial cloud cover and for recovering scenes from the Landsat 7 archive that are impacted by the SLC failure. The STARFM data fusion method can help to mitigate the dearth of high spatial-temporal resolution land surface temperature data from currently available satellite systems.

This study suggests that satellite retrievals of ET at the Landsat scale can be used to analyze water use variability over a heterogeneous forested landscape in response to stand age and vegetation composition. The estimates of ET at a high resolution provide insight of seasonal water balances and thus offer useful information for local water resource management. Comparing with traditional forest ET estimation methods, this study describes an accurate, efficient and potentially real-time remote sensing method for estimating landscape-level ET which is suitable for operational applications.

\section{Data availability}

The MODIS data were downloaded from https://reverb.echo. nasa.gov/. The Landsat data were obtained from USGS (https://earthexplorer.usgs.gov/). The $30 \mathrm{~m}$ land cover map was available at https://www.mrlc.gov/nlcd2006.php. The flux tower data were obtained from Dr. Noormets and can also be downloaded from Ameriflux (http://ameriflux-data. lbl.gov:8080/SitePages/siteInfo.aspx?US-NC2). The pine plantation stand age maps and tree planting history were obtained from the Weyerhaeuser Company.

Competing interests. The authors declare that they have no conflict of interest.

Acknowledgements. This work was funded in part by a grant from NASA (NNH14AX36I). We thank the Weyerhaeuser Company for providing stand age data. The US Department of Agriculture (USDA) prohibits discrimination in all its programs and activities on the basis of race, color, national origin, age, disability, and where applicable, sex, marital status, familial status, parental status, religion, sexual orientation, genetic information, political beliefs, reprisal or because all or part of an individual's income is derived from any public assistance program. (Not all prohibited bases apply to all programs.) Persons with disabilities who require alternative means for communication of program information (Braille, large print, audiotape, etc.) should contact USDA's TARGET Center at (202) 720-2600 (voice and TDD). To file a complaint of discrimination, write to USDA, Director, Office of Civil Rights, 1400 Independence Avenue, S.W., Washington, D.C. 20250-9410, or call (800) 795-3272 (voice) or (202) 7206382 (TDD). USDA is an equal opportunity provider and employer.

Edited by: Y. Chen

Reviewed by: two anonymous referees

\section{References}

Abramopoulos, F., Rosenzweig, C., and Choudhury, B.: Improved ground hydrology calculations for global climate models (GCMs): Soil water movement and evapotranspiration, J. Climate, 1, 921-941, 1988.

Allen, R. G., Pereira, L. S., Raes, D., and Smith, M.: Crop evapotranspiration - Guidelines for computing crop water requirements-FAO Irrigation and drainage paper 56, FAO, Rome, 300, D05109, 1998.

Anderson, M. C., Norman, J. M., Diak, G. R., Kustas, W. P., and Mecikalski, J. R.: A two-source time-integrated model for estimating surface fluxes using thermal infrared remote sensing, Remote Sens. Environ., 60, 195-216, 1997. 
Anderson, M. C., Norman, J. M., Mecikalski, J. R., Torn, R. D., Kustas, W. P., and Basara, J. B.: A multiscale remote sensing model for disaggregating regional fluxes to micrometeorological scales, J. Hydrometeorol., 5, 343-363, 2004.

Anderson, M. C., Norman, J. M., Mecikalski, J. R., Otkin, J. A., and Kustas, W. P.: A climatological study of evapotranspiration and moisture stress across the continental United States based on thermal remote sensing: 1. Model formulation, J. Geophys. Res., 112, D10117, doi:10.1029/2006JD007506, 2007a.

Anderson, M. C., Kustas, W. P., and Norman, J. M.: Upscaling Flux Observations from Local to Continental Scales Using Thermal Remote Sensing, Agron. J., 99, 240-254, doi:10.2134/agronj2005.0096S, 2007b.

Anderson, M. C., Kustas, W. P., Norman, J. M., Hain, C. R., Mecikalski, J. R., Schultz, L., González-Dugo, M. P., Cammalleri, C., d'Urso, G., Pimstein, A., and Gao, F.: Mapping daily evapotranspiration at field to continental scales using geostationary and polar orbiting satellite imagery, Hydrol. Earth Syst. Sci., 15, 223-239, doi:10.5194/hess-15-223-2011, 2011.

Anderson, M. C., Kustas, W. P., Alfieri, J. G., Gao, F., Hain, C., Prueger, J. H., Evett, S., Colaizzi, P., Howell, T., and Chávez, J. L.: Mapping daily evapotranspiration at Landsat spatial scales during the BEAREX'08 field campaign, Adv. Water Resour., 50, 162-177, doi:10.1016/j.advwatres.2012.06.005, 2012a.

Anderson, M. C., Allen, R. G., Morse, A., and Kustas, W. P.: Use of Landsat thermal imagery in monitoring evapotranspiration and managing water resources, Remote Sens. Environ., 122, 50-65, doi:10.1016/j.rse.2011.08.025, 2012b.

Anderson, M. C., Cammalleri, C., Hain, C. R., Otkin, J., Zhan, X., and Kustas, W.: Using a diagnostic soil-plant-atmosphere model for monitoring drought at field to continental scales, Procedia Environ. Sci., 19, 47-56, doi:10.1016/j.proenv.2013.06.006, 2013.

Bailey, R.: Description of the Ecoregions of the United States, USDA Forest Service, Washington, 1995.

Baldocchi, D., Falge, E., Gu, L., Olson, R., Hollinger, D., Running, S., Anthoni, P., Bernhofer, C., Davis, K., and Evans, R.: FLUXNET: A new tool to study the temporal and spatial variability of ecosystem-scale carbon dioxide, water vapor, and energy flux densities, B. Am. Meteorol. Soc., 82, 2415-2434, 2001.

Beven, K. and Freer, J.: Equifinality, data assimilation, and uncertainty estimation in mechanistic modelling of complex environmental systems using the GLUE methodology, J. Hydrol., 249, 11-29, 2001.

Brutsaert, W. H.: Evaporation in the Atmosphere, D. Reidel pub. Comp, Dordrecht, Boston, London, 1982.

Cammalleri, C., Anderson, M. C., Gao, F., Hain, C. R., and Kustas, W. P.: A data fusion approach for mapping daily evapotranspiration at field scale, Water Resour. Res., 49, 4672-4686, doi:10.1002/wrcr.20349, 2013.

Cammalleri, C., Anderson, M. C., Gao, F., Hain, C. R., and Kustas, W. P.: Mapping daily evapotranspiration at field scales over rainfed and irrigated agricultural areas using remote sensing data fusion, Agr. Forest Meteorol., 186, 1-11, doi:10.1016/j.agrformet.2013.11.001, 2014.

Chen, F. and Dudhia, J.: Coupling an advanced land surfacehydrology model with the Penn State-NCAR MM5 modeling system. Part I: Model implementation and sensitivity, Mon. Weather Rev., 129, 569-585, 2001.
Chen, J., Zhu, X., Vogelmann, J. E., Gao, F., and Jin, S.: A simple and effective method for filling gaps in Landsat ETM+ SLC-off images, Remote Sens. Environ., 115, 1053-1064, 2011.

Cienciala, E. and Lindroth, A.: Gas-exchange and sap flow measurements of Salix viminalis trees in short-rotation forest, Trees, 9, 295-301, 1995.

Cuenca, R. H., Stangel, D. E., and Kelly, S. F.: Soil water balance in a boreal forest, J. Geophys. Res.-Atmos., 102, 29355-29365, 1997.

Domec, J.-C., Sun, G., Noormets, A., Gavazzi, M. J., Treasure, E. A., Cohen, E., Swenson, J. J., McNulty, S. G., and King, J. S.: A comparison of three methods to estimate evapotranspiration in two contrasting Loblolly Pine plantations: age-related changes in water use and drought sensitivity of evapotranspiration components, Forest Sci., 58, 497-512, doi:10.5849/forsci.11-051, 2012.

Duchemin, B., Hadria, R., Erraki, S., Boulet, G., Maisongrande, P., Chehbouni, A., Escadafal, R., Ezzahar, J., Hoedjes, J. C. B., and Kharrou, M. H.: Monitoring wheat phenology and irrigation in Central Morocco: On the use of relationships between evapotranspiration, crops coefficients, leaf area index and remotely-sensed vegetation indices, Agr. Water Manage., 79, 1-27, 2006.

Fang, Y., Sun, G., Caldwell, P., McNulty, S. G., Noormets, A., Domec, J., King, J., Zhang, Z., Zhang, X., and Lin, G.: Monthly land cover specific evapotranspiration models derived from global eddy flux measurements and remote sensing data, Ecohydrology, doi:10.1002/eco.1629, in press, 2015.

Friedl, M. A., McIver, D. K., Hodges, J. C. F., Zhang, X. Y., Muchoney, D., Strahler, A. H., Woodcock, C. E., Gopal, S., Schneider, A., Cooper, A., Baccini, A., Gao, F., and Schaaf, C.: Global land cover mapping from MODIS: algorithms and early results, Remote Sens. Environ., 83, 287-302, doi:10.1016/S00344257(02)00078-0, 2002.

Fry, J., Xian, G., Jin, S., Dewitz, J., Homer, C., Yang, L., Barnes, C., Herold, N., and Wickham, J.: Completion of the 2006 national land cover database for the conterminous United States, publ. by: Multi-Resolution L. Charact. Consortium, PE \& RS, Vol. 77, 858-864, http//www.mrlc.gov/nlcd2006.php (last access: 24 October 2013), 2011.

Gao, F., Masek, J., Schwaller, M., and Hall, F.: On the blending of the Landsat and MODIS surface reflectance: Predicting daily Landsat surface reflectance, IEEE T. Geosci. Remote, 44, 22072218, 2006.

Gao, F., Morisette, J. T., Wolfe, R. E., Ederer, G., Pedelty, J., Masuoka, E., Myneni, R., Tan, B., and Nightingale, J.: An algorithm to produce temporally and spatially continuous MODISLAI time series, IEEE T. Geosci. Remote, 5, 60-64, 2008.

Gao, F., Kustas, W. P., and Anderson, M. C.: A data mining approach for sharpening thermal satellite imagery over land, Remote Sens., 4, 3287-3319, 2012a.

Gao, F., Anderson, M. C., Kustas, W. P., and Wang, Y.: Simple method for retrieving leaf area index from Landsat using MODIS leaf area index products as reference, J. Appl. Remote Sens., 6, 63551-63554, 2012b.

Hain, C. R., Crow, W. T., Mecikalski, J. R., Anderson, M. C., and Holmes, T.: An intercomparison of available soil moisture estimates from thermal infrared and passive microwave remote sensing and land surface modeling, J. Geophys. Res., 116, D15107, doi:10.1029/2011JD015633, 2011. 
Hain, C. R., Crow, W. T., Anderson, M. C., and Yilmaz, M. T.: Diagnosing neglected soil moisture source/sink processes via a thermal infrared-based two-source energy balance model, J. Hydrometeorol., 16, 1070-1086, 2015.

Hanson, P. J., Amthor, J. S., Wullschleger, S. D., Wilson, K. B., Grant, R. F., Hartley, A., Hui, D., Hunt E Raymond, J., Johnson, D. W., and Kimball, J. S.: Oak forest carbon and water simulations: model intercomparisons and evaluations against independent data, Ecol. Monogr., 74, 443-489, 2004.

Huete, A., Didan, K., Miura, T., Rodriguez, E. P., Gao, X., and Ferreira, L. G.: Overview of the radiometric and biophysical performance of the MODIS vegetation indices, Remote Sens. Environ., 83, 195-213, 2002.

Johnson, L. F. and Trout, T. J.: Satellite NDVI assisted monitoring of vegetable crop evapotranspiration in California's San Joaquin valley, Remote Sens., 4, 439-455, 2012.

Kalma, J. D., McVicar, T. R., and McCabe, M. F.: Estimating land surface evaporation: A review of methods using remotely sensed surface temperature data, Surv. Geophys., 29, 421-469, 2008.

Kannan, N., White, S. M., Worrall, F., and Whelan, M. J.: Sensitivity analysis and identification of the best evapotranspiration and runoff options for hydrological modelling in SWAT-2000, J. Hydrol., 332, 456-466, 2007.

Klein, T., Rotenberg, E., Cohen Hilaleh, E., RazYaseef, N., Tatarinov, F., Preisler, Y., Ogée, J., Cohen, S., and Yakir, D.: Quantifying transpirable soil water and its relations to tree water use dynamics in a water limited pine forest, Ecohydrology, 7, 409419, 2014.

Kuczera, G.: Prediction of water yield reductions following a bushfire in ash-mixed species eucalypt forest, J. Hydrol., 94, 215-236, 1987.

Kustas, W. P. and Anderson, M.: Advances in thermal infrared remote sensing for land surface modeling, Agr. Forest Meteorol., 149, 2071-2081, doi:10.1016/j.agrformet.2009.05.016, 2009.

Kustas, W. P. and Norman, J. M.: Evaluation of soil and vegetation heat flux predictions using a simple two-source model with radiometric temperatures for partial canopy cover, Agr. Forest Meteorol., 94, 13-29, 1999.

Kustas, W. P. and Norman, J. M.: A two-source energy balance approach using directional radiometric temperature observations for sparse canopy covered surfaces, Agron. J., 92, 847-854, 2000.

Lu, J., Sun, G., McNulty, S. G., and Amatya, D. M.: Modeling actual evapotranspiration from forested watersheds across the southeastern united states, J. Am. Water Resour. Assoc., 39, 886896, 2003.

Matheussen, B., Kirschbaum, R. L., Goodman, I. A., O’Donnell, G. M., and Lettenmaier, D. P.: Effects of land cover change on streamflow in the interior Columbia River Basin (USA and Canada), Hydrol. Process., 14, 867-885, 2000.

Méndez Barroso, L. A., Vivoni, E. R., Robles Morua, A., Mascaro, G., Yépez, E. A., Rodríguez, J. C., Watts, C. J., Garatuza Payán, J., and Saíz Hernández, J. A.: A modeling approach reveals differences in evapotranspiration and its partitioning in two semiarid ecosystems in northwest Mexico, Water Resour. Res., 50, 3229-3252, 2014.

Murakami, S., Tsuboyama, Y., Shimizu, T., Fujieda, M., and Noguchi, S.: Variation of evapotranspiration with stand age and climate in a small Japanese forested catchment, J. Hydrol., 227, 114-127, 2000.

Mutiibwa, D. and Irmak, S.: AVHRR NDVI based crop coefficients for analyzing long term trends in evapotranspiration in relation to changing climate in the US High Plains, Water Resour. Res., 49, 231-244, 2013.

Myneni, R. B., Hoffman, S., Knyazikhin, Y., Privette, J. L., Glassy, J., Tian, Y., Wang, Y., Song, X., Zhang, Y., Smith, G. R., Lotsch, A., Friedl, M., Morisette, J. T., Votava, P., Nemani, R. R., and Running, S. W.: Global products of vegetation leaf area and fraction absorbed PAR from year one of MODIS data, Remote Sens. Environ., 83, 214-231, doi:10.1016/S00344257(02)00074-3, 2002.

Nemani, R. and Running, S.: Estimation of Regional Surface Resistance to Evapotranspiration from NDVI and Thermal-IR AVHRR Data, J. Appl. Meteorol., 28, 276-284, 1988.

Nemani, R., Pierce, L., Running, S., and Band, L.: Forest Ecosystem Processes at the Watershed Scale - Sensitivity to RemotelySensed Leaf-Area Index Estimates, Int. J. Remote Sens., 14, 2519-2534, 1993.

Noormets, A., McNulty, S. G., DeForest, J. L., Sun, G., Li, Q., and Chen, J.: Drought during canopy development has lasting effect on annual carbon balance in a deciduous temperate forest, New Phytol., 179, 818-828, 2008.

Noormets, A., Gavazzi, M. J., Mcnulty, S. G., Domec, J.C., Sun, G., King, J. S., and Chen, J.: Response of carbon fluxes to drought in a coastal plain loblolly pine forest, Global Change Biol., 16, 272-287, doi:10.1111/j.13652486.2009.01928.x, 2010.

Norman, J. M., Kustas, W. P., and Humes, K. S.: Source approach for estimating soil and vegetation energy fluxes in observations of directional radiometric surface temperature, Agr. Forest Meteorol., 77, 263-293, doi:10.1016/0168-1923(95)02265-Y, 1995.

Norman, J. M., Anderson, M. C., Kustas, W. P., French, A. N., Mecikalski, J., Torn, R., Diak, G. R., Schmugge, T. J., and Tanner, B. C. W.: Remote sensing of surface energy fluxes at 10 1-m pixel resolutions, Water Resour. Res., 39, 1221, doi:10.1029/2002WR001775, 2003.

Olioso, A., Chauki, H., Courault, D., and Wigneron, J.-P.: Estimation of evapotranspiration and photosynthesis by assimilation of remote sensing data into SVAT models, Remote Sens. Environ., 68, 341-356, 1999.

Pan, M., Sahoo, A. K., Troy, T. J., Vinukollu, R. K., Sheffield, J., and Wood, E. F.: Multisource estimation of long-term terrestrial water budget for major global river basins, J. Climate, 25, 31913206, 2012.

Pereira, L. S., Oweis, T., and Zairi, A.: Irrigation management under water scarcity, Agr. Water Manage., 57, 175-206, 2002.

Roberts, S., Vertessy, R., and Grayson, R.: Transpiration from Eucalyptus sieberi (L. Johnson) forests of different age, Forest Ecol. Manage., 143, 153-161, 2001.

Roy, D. P., Ju, J., Lewis, P., Schaaf, C., Gao, F., Hansen, M., and Lindquist, E.: Multi-temporal MODIS-Landsat data fusion for relative radiometric normalization, gap filling, and prediction of Landsat data, Remote Sens. Environ., 112, 3112-3130, 2008.

Schaaf, C. B., Liu, J., Gao, F., and Strahler, A. H.: Aqua and Terra MODIS albedo and reflectance anisotropy products, in: Land Remote Sensing and Global Environmental Change, Springer, 549$561,2010$. 
Scott, R. L., Huxman, T. E., Cable, W. L., and Emmerich, W. E.: Partitioning of evapotranspiration and its relation to carbon dioxide exchange in a Chihuahuan Desert shrubland, Hydrol. Process., 20, 3227-3243, 2006.

Semmens, K. A., Anderson, M. C., Kustas, W. P., Gao, F., Alfieri, J. G., McKee, L., Prueger, J. H., Hain, C. R., Cammalleri, C., and Yang, Y.: Monitoring daily evapotranspiration over two California vineyards using Landsat 8 in a multi-sensor data fusion approach, Remote Sens. Environ., 85, 155-170, doi:10.1016/j.rse.2015.10.025, 2015.

Shaw, R. H. and Pereira, A. R.: Aerodynamic roughness of a plant canopy: a numerical experiment, Agr. Meteorol., 26, 51-65, 1982.

Smith, D. M. and Allen, S. J.: Measurement of sap flow in plant stems, J. Exp. Bot., 47, 1833-1844, 1996.

Sun, G., Noormets, A., Gavazzi, M. J., McNulty, S. G., Chen, J., Domec, J.-C., King, J. S., Amatya, D. M., and Skaggs, R. W.: Energy and water balance of two contrasting loblolly pine plantations on the lower coastal plain of North Carolina, USA, Forest Ecol. Manage., 259, 1299-1310, 2010.

Sun, G., Alstad, K., Chen, J., Chen, S., Ford, C. R., Lin, G., Liu, C., Lu, N., Mcnulty, S. G., Miao, H., Noormets, A., Vose, J. M., Wilske, B., Zeppel, M., and Zhang, Y.: A general predictive model for estimating monthly ecosystem evapotranspiration, Ecohydrology, 255, 245-255, doi:10.1002/eco.194, 2011a.

Sun, G., Caldwell, P., Noormets, A., McNulty, S. G., Cohen, E., Moore Myers, J., Domec, J.-C., Treasure, E., Mu, Q., Xiao, J., John, R., and Chen, J.: Upscaling key ecosystem functions across the conterminous United States by a watercentric ecosystem model, J. Geophys. Res., 116, G00J05, doi:10.1029/2010JG001573, 2011b.

Sun, Q., Wang, Z., Li, Z., Erb, A., and Schaaf, C. B.: Evaluation of the global MODIS 30 arc-second spatially and temporally complete snow-free land surface albedo and reflectance anisotropy dataset, Int. J. Appl. Earth Obs. Geoinf., 58, 36-49, doi:10.1016/j.jag.2017.01.011, 2017.

Tague, C. L. and Band, L. E.: RHESSys: Regional hydro-ecologic simulation system-an object-oriented approach to spatially distributed modeling of carbon, water, and nutrient cycling, Earth Interact., 8, 1-42, 2004.

Tague, C. L., Choate, J. S., and Grant, G.: Parameterizing subsurface drainage with geology to improve modeling streamflow responses to climate in data limited environments, Hydrol. Earth Syst. Sci., 17, 341-354, doi:10.5194/hess-17-341-2013, 2013.
Tian, H., Chen, G., Liu, M., Zhang, C., Sun, G., Lu, C., Xu, X., Ren, W., Pan, S., and Chappelka, A.: Model estimates of net primary productivity, evapotranspiration, and water use efficiency in the terrestrial ecosystems of the southern United States during 1895-2007, Forest Ecol. Manage., 259, 13111327, doi:10.1016/j.foreco.2009.10.009, 2010.

Vertessy, R. A., Watson, F. G. R., and Sharon, K. O.: Factors determining relations between stand age and catchment water balance in mountain ash forests, Forest Ecol. Manage., 143, 13-26, 2001.

Von Bertalanffy, L.: General systems theory, Braziller, New York, 1968.

Wan, Z., Zhang, Y., Zhang, Q., and Li, Z.-L.: Quality assessment and validation of the MODIS global land surface temperature, Int. J. Remote Sens., 25, 261-274, 2004.

Wang, K. and Dickinson, R. E.: A review of global terrestrial evapotranspiration: observation, modelling, climatology, and climatic variability, Rev. Geophys., 50, 1-54, doi:10.1029/2011RG000373, 2012.

Wickham, J. D., Stehman, S. V, Gass, L., Dewitz, J., Fry, J. A., and Wade, T. G.: Accuracy assessment of NLCD 2006 land cover and impervious surface, Remote Sens. Environ., 130, 294-304, 2013.

Williams, C. A., Reichstein, M., Buchmann, N., Baldocchi, D., Beer, C., Schwalm, C., Wohlfahrt, G., Hasler, N., Bernhofer, C., and Foken, T.: Climate and vegetation controls on the surface water balance: Synthesis of evapotranspiration measured across a global network of flux towers, Water Resour. Res., 48, W00L11, doi:10.1029/2011WR010809, 2012.

Wilson, K. B., Hanson, P. J., Mulholland, P. J., Baldocchi, D. D., and Wullschleger, S. D.: A comparison of methods for determining forest evapotranspiration and its components: sap-flow, soil water budget, eddy covariance and catchment water balance, Agr. Forest Meteorol., 106, 153-168, 2001.

Wullschleger, S. D., Meinzer, F. C., and Vertessy, R. A.: A review of whole-plant water use studies in tree, Tree Physiol., 18, 499-512, 1998.

Yilmaz, M. T., Anderson, M. C., Zaitchik, B. F., Hain, C. R., Crow, W. T., Ozdogan, M., and Chung, J. A.: Comparison of prognostic and diagnostic surface flux modeling approaches over the Nile River Basin, Water Resour. Res., 50, 386-408, 2014.

Zhang, L., Hickel, K., Dawes, W. R., Chiew, F. H. S., Western, A. W., and Briggs, P. R.: A rational function approach for estimating mean annual evapotranspiration, Water Resour. Res., 40, W02502, doi:10.1029/2003WR002710, 2004.

Zhu, Z. and Woodcock, C. E.: Object-based cloud and cloud shadow detection in Landsat imagery, Remote Sens. Environ., 118, 8394, doi:10.1016/j.rse.2011.10.028, 2012. 